\title{
Effect of Water Content in Ethylene Glycol Solvent on the Size of ZnO Nanoparticles Prepared Using Microwave Solvothermal Synthesis
}

\author{
Jacek Wojnarowicz, ${ }^{1}$ Agnieszka Opalinska, ${ }^{1}$ Tadeusz Chudoba, ${ }^{1}$ Stanislaw Gierlotka, \\ Roman Mukhovskyi, ${ }^{1}$ Elzbieta Pietrzykowska, ${ }^{1,2}$ Kamil Sobczak, $^{3}$ and Witold Lojkowski ${ }^{1}$ \\ ${ }^{1}$ Institute of High Pressure Physics, Polish Academy of Science, Sokolowska 29/37, 01-142 Warsaw, Poland \\ ${ }^{2}$ Faculty of Materials Science and Engineering, Warsaw University of Technology, Woloska 141, 02-507 Warsaw, Poland \\ ${ }^{3}$ Institute of Physics, Polish Academy of Science, Aleja Lotników 32/46, 02-668 Warsaw, Poland \\ Correspondence should be addressed to Jacek Wojnarowicz; jacek.wojnarowicz@tlen.pl
}

Received 11 March 2016; Revised 30 May 2016; Accepted 8 June 2016

Academic Editor: Muhammet S. Toprak

Copyright ( $(2016$ Jacek Wojnarowicz et al. This is an open access article distributed under the Creative Commons Attribution License, which permits unrestricted use, distribution, and reproduction in any medium, provided the original work is properly cited.

\begin{abstract}
Zinc oxide nanoparticles (ZnO NPs) were obtained by the microwave solvothermal synthesis (MSS) method. The precursor of the MSS reaction was a solution of hydrated zinc acetate in ethylene glycol with water addition. It was proved that by controlling the water concentration in the precursor it was possible to control the size of ZnO NPs in a programmed manner. The less the water content in the precursor, the smaller the size of ZnO NPs obtained. The obtained NPs with the average particle size ranging from $25 \mathrm{~nm}$ to $50 \mathrm{~nm}$ were characterised by homogeneous morphology and a narrow distribution of particle sizes. The following parameters of the obtained ZnO NPs were determined: pycnometric density, specific surface area, phase purity, chemical composition, lattice parameters, average particle size, and particle size distribution. The average size of ZnO NPs was determined using Scherrer's formula, Nanopowder XRD Processor Demo web application, by converting the results of the specific surface area, and TEM tests using the dark field technique. ZnO morphology and structure were determined using scanning electron microscopy (SEM) and transmission electron microscopy (TEM). The test performed by the X-ray powder diffraction (XRD) confirmed that crystalline $\mathrm{ZnO}$, pure in terms of phase, had been obtained.
\end{abstract}

\section{Introduction}

The past decades saw a dynamic development of nanotechnology [1]. The essence of nanotechnology is to make use of the correlation between matter properties and matter size, particularly when at least one dimension is below $100 \mathrm{~nm}$ [2]. This opens a large room for scientific discoveries and new applications. Currently nanotechnology not only is developed in scientific laboratories, but also accompanies us in everyday life [3].

The nanotechnology market is growing rapidly [4]. A major part of that market is the market of nanoparticles, that is, particles of matter sized below $100 \mathrm{~nm}$. Nano- $\mathrm{ZnO}$ has a large market share among nanoparticles [5]. Owing to its unique physical and chemical properties, $\mathrm{ZnO}$ is a multifunctional material $[6,7]$. It is a II-VI semiconductor. Thanks to the wide band gap of $3.37 \mathrm{eV}$, high exciton binding energy $(60 \mathrm{meV})$, and thermal stability, it is an attractive material for electronics, optoelectronics, and laser technologies, for example, lasers operating in the ultraviolet range, UV radiation detectors, or UV emitting diodes [8-12]. $\mathrm{ZnO}$ is a perfect screening material against UV radiation and has a wide characteristic of UV absorption and is a photostable UVA/UVB sunblock agent [13]. It is a piezoelectric material $[14,15]$. Zinc oxide is a promising material for manufacturing solar cells [16] and sensors of such gases as $\mathrm{NH}_{3}, \mathrm{NO}_{2}, \mathrm{H}_{2} \mathrm{~S}, \mathrm{CO}_{2}, \mathrm{CO}, \mathrm{C}_{2} \mathrm{H}_{5} \mathrm{OH}$, and liquefied petroleum gas (LPG) [17-24]. The biocompatibility, antibacterial action, and biodegradability of $\mathrm{ZnO}$ make it an object of great interest of biomedicine [25-27]. $\mathrm{ZnO}$ 
layers are also applied as transparent conductive materials, nanostructured electrodes for batteries, and components of devices with acoustic surface wave [28-31]. After doping, it displays new, for example, paramagnetic, ferromagnetic, and magnetooptical, properties $[10,16,32-34]$. It is widely used as a component of various products such as rubber, pigments, cements, plastics, sealants, and paints. It is also a component of pharmaceutical products and cosmetics, for example, baby powders, toothpastes and tooth dressings, sunscreens, and skin protection balms. It is used as a catalyst in organic reactions, for example, for synthesis of methanol from $\mathrm{CO}_{2}$ and $\mathrm{H}_{2}$ [35].

The properties of $\mathrm{ZnO}$ nanostructures are strongly dependent on their size and shape. Young's modulus of $\mathrm{ZnO}$ nanowires changes considerably when the shape of their cross section changes [36]. The size of $\mathrm{ZnO}$ particles exerts a considerable impact above all on the equilibrium constant and the thermodynamic properties of the reaction [37], photoluminescence [38], band gap [39], UV absorption [40], and toxicity [41, 42]. Particularly piezoelectric parameters may be greater by several orders of magnitude in comparison with $\mathrm{ZnO}$ bulk material [36]. As a result, such methods of nano- $\mathrm{ZnO}$ synthesis are needed that enable a precise control of the average particle size and obtaining a narrow size distribution. In order to obtain the required performance characteristics, it is also necessary that the material is fully crystalline and characterised by high purity.

The relevant literature includes numerous chemical, physical, and biological methods of producing $\mathrm{ZnO}$ nanostructures of different shapes, for example, spherical [43, 44], straw bundle, wide chrysanthemum, nanorod-based microspheres [45], nanowires [46], nanobelts [47], columns [48], tetrapods [49], helices [50], polyhedral cages and shells [51], tubes, rods, and needles [43, 44, 52], flowers [44, 53], and irregular crystals and spherical to hexagonal prisms [54]. The most often employed laboratory methods of obtaining ZnO NPs are calcination, precipitation, sol-gel, electrolytic obtaining, and hydrothermal and solvothermal synthesis [55]. Microwave hydrothermal and solvothermal synthesis count as ones of the most popular methods of obtaining nanomaterials $[56,57]$. They are systematically developed by constructing new types of reactors, for example, stop-flow and continuous-flow ones [58-63].

Syntheses of metal oxide nanoparticles in organic solvents have been very popular recently [64-66]. The main reasons for choosing organic solvents in the synthesis of nano$\mathrm{ZnO}$ are nucleation and growth of nanoparticles in high boiling polyols such as ethylene glycol (EG), diethylene glycol (DEG), tetraethylene glycol (TEG), or glycerol. In this case the polyol acts as the solvent and the stabilising agent, which restricts particle growth and suppresses particle agglomeration and aggregation. Organic solvents also enable obtaining uniformly doped $\mathrm{ZnO}$ NPs, for example, with $\mathrm{Co}^{2+}$ or $\mathrm{Mn}^{2+}$ ions, without precipitation of foreign phases [32, 33]. In addition, the synthesis is easy to perform and does not require multistage steps or advanced experimental conditions or professional reactors.

The relevant literature offers several methods of controlling the size of $\mathrm{ZnO}$ NPs obtained in solvothermal synthesis, that is, in organic solvents. Chieng and Loo [67] described a single-stage synthesis with control of $\mathrm{ZnO}$ NPs size, where, as the reaction precursors, they used solutions obtained by dissolving $\mathrm{Zn}\left(\mathrm{CH}_{3} \mathrm{COO}\right)_{2} \cdot 2 \mathrm{H}_{2} \mathrm{O}$ in $\mathrm{EG}, \mathrm{DEG}$, and TEG. The average size of the obtained $\mathrm{ZnO}$ NPs in EG was $20 \mathrm{~nm}$, in DEG $39 \mathrm{~nm}$, and in TEG $69 \mathrm{~nm}$. The size control of $\mathrm{ZnO}$ NPs was explained by the authors with the impact of the chain length of the polyols used. The average particle size of $\mathrm{ZnO}$ was increased in line with the increased glycol chain length. Lian et al. in their paper [68] described a synthesis of $\mathrm{ZnO}$ NPs with controllable size via a solvothermal method using a mixed solvent system. The average size of the NPs can be tailored within the range from $15 \mathrm{~nm}$ to $25 \mathrm{~nm}$ by adjusting the volume ratio of ethanol/EG. Wang et al. [69] were ones of the first scholars to describe the solvothermal synthesis with controlled size of $\mathrm{ZnO}$ microstructures by adding water to the organic solvent. A solution of zinc acetate dissolved in methanol was used as the reaction precursor. However, $\mathrm{ZnO}$ microstructures obtained in that manner contained foreign phases and were heterogeneous. Wang suggested that the mechanism of $\mathrm{ZnO}$ size control by changing the $\mathrm{H}_{2} \mathrm{O}$ content in the precursor was the probable impact of water on the simultaneous course of hydrolysis of $\mathrm{Zn}\left(\mathrm{CH}_{3} \mathrm{COO}\right)_{2}$ as well as of the generated intermediates. Bitenc and Crnjak Orel [70] described a one-step solution phase preparation method used for the preparation of nano- and submicrometre-sized $\mathrm{ZnO}$. As the reaction precursor they used a mixture of $\mathrm{Zn}\left(\mathrm{NO}_{3}\right)_{2} \cdot 6 \mathrm{H}_{2} \mathrm{O}$ and urea in solvents. The paper shows a synthesis of $\mathrm{ZnO}$ structures which can be controlled by changing the types of solvents, water, and water/polyol, where a part of the water is substituted with EG, DEG, and TEG. It was indicated in the example of EG that the size of the structures decreased in line with increasing volume/concentration of the added EG. The publication by Li et al. [71] is another one which confirms the possibility of controlling the size of $\mathrm{ZnO}$ NPs by changing water concentration in the precursor suspension obtained by mixing $\mathrm{Zn}\left(\mathrm{CH}_{3} \mathrm{COO}\right)_{2}+\mathrm{NaOH}$ + tetradecane in EG. The authors obtain ZnO NPs by a multistage method within the size range between $18 \mathrm{~nm}$ and $436 \mathrm{~nm}$. However, based on the provided results, the phase purity of all obtained samples of ZnO NPs cannot be confirmed.

It was determined that water exerts a significant impact on the course of solvothermal synthesis and even small amounts of $\mathrm{H}_{2} \mathrm{O}$ in organic solvents promote crystal growth [72]. However, papers of most scholars do not take into account the presence and changes in the concentration of water in the precursor despite the fact that water is supplied to the precursor in two ways: with a hydrated salt, for example, $\mathrm{Zn}\left(\mathrm{CH}_{3} \mathrm{COO}\right)_{2} \cdot 2 \mathrm{H}_{2} \mathrm{O}$, and together with an organic solvent wherein it occurs in trace quantities $[67,68]$. The mechanism of growth and size control of $\mathrm{ZnO}$ crystals in organic solvents has not been unambiguously explained so far [73-77]. It should be remembered that each mechanism of $\mathrm{ZnO}$ synthesis should be treated individually. This results from the diversity of precursors used and at the same time from the multitude of obtainable intermediates belonging to the group of metalorganic compounds [78]. 
In the present paper we report the control of the size of nano- $\mathrm{ZnO}$ particles in a simple chemical reaction, where the only ingredients of the reaction substrates are zinc acetate, ethylene glycol, and water. Although water is always present in ethylene glycol and zinc acetate, its precise amount can be controlled in experimental conditions. The particle size is a function of the amount of water in the precursor. For the synthesis, we used the microwave solvothermal synthesis (MSS) method [58].

\section{Experimental Methods}

2.1. Chemicals. Hydrated zinc acetate $\left(\mathrm{Zn}\left(\mathrm{CH}_{3} \mathrm{COO}\right)_{2}\right.$. $2 \mathrm{H}_{2} \mathrm{O}$ ), analytically pure, SKU: 112654906-1KG, and ethylene glycol (ethane-1,2-diol, $\mathrm{C}_{2} \mathrm{H}_{4}(\mathrm{OH})_{2}$ ), pure, SKU: 114466303$5 \mathrm{~L}$, purchased from Chempur, were used. The reagents were used without additional purification. Deionised water with specific conductance below $0.1 \mu \mathrm{S} / \mathrm{cm}$ was obtained using a deioniser (HLP 20UV, Hydrolab, Poland).

2.2. Preparation of $\mathrm{ZnO}$ Nanopowders. Zinc oxide was obtained by the microwave solvothermal synthesis (MSS) technique [32]. The reaction precursor, solution of zinc acetate in ethylene glycol (Table 1), was prepared using a hotplate magnetic stirrer (SLR, SI Analytics, Germany) at the constant temperature of $70^{\circ} \mathrm{C}$ and stirring speed of $450 \mathrm{rpm}$. After complete dissolution of zinc acetate, the solution was poured to five $100 \mathrm{~mL}$ PP containers and closed tightly. After cooling down to the ambient temperature, an analysis of water content in the precursor was carried out $\left(1.01 \%\right.$ of $\left.\mathrm{H}_{2} \mathrm{O}\right)$. An appropriate calculated amount of $\mathrm{H}_{2} \mathrm{O}$ was added to the precursor to obtain the intended water content (Table 1), and subsequently the solution was stirred again and an analysis of water content in the prepared precursor was carried out. Then $70 \mathrm{~mL}$ of the solution was poured to a $110 \mathrm{~mL}$ Teflon ${ }^{\circledR}$ reaction container and closed tightly. Thus prepared precursor in the reaction container was put into the microwave reactor. The above operations were repeated for each sample in order to achieve the following water concentrations in the precursor: $1.5 \%, 2 \%, 3 \%$, and $4 \%$.

The reaction, initiated with microwave radiation, was carried out in Magnum 02-02 reactor $(600 \mathrm{~W}, 2.45 \mathrm{GHz}$, ERTEC, Poland). The diagram of the microwave reactor structure is presented in Figure 1. The synthesis of zinc oxide in ethylene glycol is described by the following general reaction equation:

$$
\left(\mathrm{CH}_{3} \mathrm{CO}_{2}\right)_{2} \mathrm{Zn} \cdot 2 \mathrm{H}_{2} \mathrm{O} \stackrel{\mathrm{C}_{2} \mathrm{H}_{4}(\mathrm{OH})_{2}, \mathrm{H}_{2} \mathrm{O}, \mathrm{T}, \mathrm{P}}{\longrightarrow} \mathrm{ZnO}_{\downarrow}+\text { other products (liquid or gas) }
$$

The reaction duration was 25 minutes, temperature $220^{\circ} \mathrm{C}$, and power $100 \%$, and after that the reaction container was cooled down for 20 minutes. After the synthesis, the obtained powder was sedimented, rinsed three times with deionised water, centrifuged (MPW-350, MPW Med Instruments, Poland), and dried in a freeze dryer (Lyovac GT-2, SRK Systemtechnik GmbH, Germany).

2.3. X-Ray Powder Diffraction. Diffraction patterns of the Xray powder diffraction (XRD) were gathered at the room temperature within the range of 2-theta angle from $10^{\circ}$ to $100^{\circ}$ with the step of $0.02^{\circ}$, using the X-ray powder diffractometer $\left(C u K_{\alpha 1}\right)$ (X'Pert PRO, Panalytical, Netherlands) [81]. The parameters of the crystalline lattice were determined by the Rietveld method implemented in Fityk software, version 0.9.8. Based on the diffraction patterns, the size of crystallites was determined in the direction of the crystallographic axes $a$ and $c$ using Scherrer's formula in the following form:

$$
D_{h k l}=\frac{K \cdot \lambda}{\beta \cdot \cos \theta_{h k l}}
$$

In the above equation, Scherrer's formula, $D_{h k l}$ is the volume weighted crystallite size $(\mathrm{nm}) ; K$ is the shape factor $(k=0.9)$; $\lambda$ is the wavelength of the $\mathrm{X}$-rays $\left(\lambda=0.154056 \mathrm{~nm}\right.$ for $C u K_{\alpha 1}$ radiation); $\theta_{h k l}$ is the Bragg diffraction angle $\left({ }^{\circ}\right) ; \beta$ is the broadening of the $h k l$ diffraction peak measured at half of its maximum intensity (in radians) [82].
2.4. Crystallite Size Distribution. The analysis of XRD peak profile was performed using the analytical formula for polydispersive powders [83]. While Scherrer method provides a single size parameter, this technique provides four parameters: average crystallite size, error of the average crystallite size, dispersion of size, and error of dispersion of sizes. Hence, a full crystallite size distribution curve and an estimation of "thickness" of this curve (error bars) are obtained.

The online tool Nanopowder XRD Processor Demo (http://science24.com/xrd) is a webpage where diffraction files can be directly dropped [84]. Files are processed on a server to extract the crystallite size distribution for XRD peaks [80]. Unlike the standard fitting, the tool does not act in the reciprocal space at all but solves sets of equations in a few auxiliary spaces simultaneously. This allows an analysis of XRD data with heavily convoluted reciprocal space peaks.

2.5. Measurement of Density and Specific Surface Area. Density measurements were carried out using the helium pycnometer [85] (AccuPyc II 1340, FoamPyc V1.06, Micromeritics, USA), the measurements were carried out in accordance with ISO 12154:2014 at temperature of $25 \pm 2^{\circ} \mathrm{C}$. Density of a material obtained using helium pycnometry is called skeleton density, pycnometric density, true density, and helium density in the relevant literature. The specific surface area of NPs was determined using the surface analyser (Gemini 2360, V 2.01, Micromeritics, USA) by gas adsorption method based on the linear form of the BET (Brunauer-Emmett-Teller) 


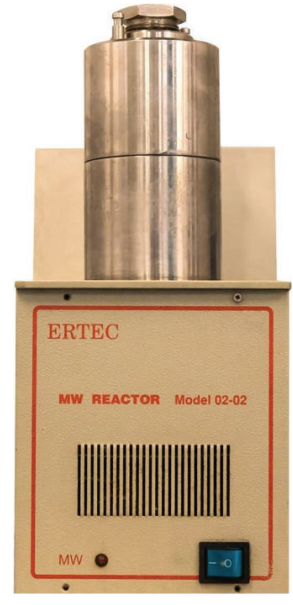

(a)

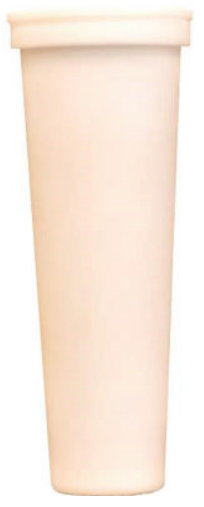

(b)

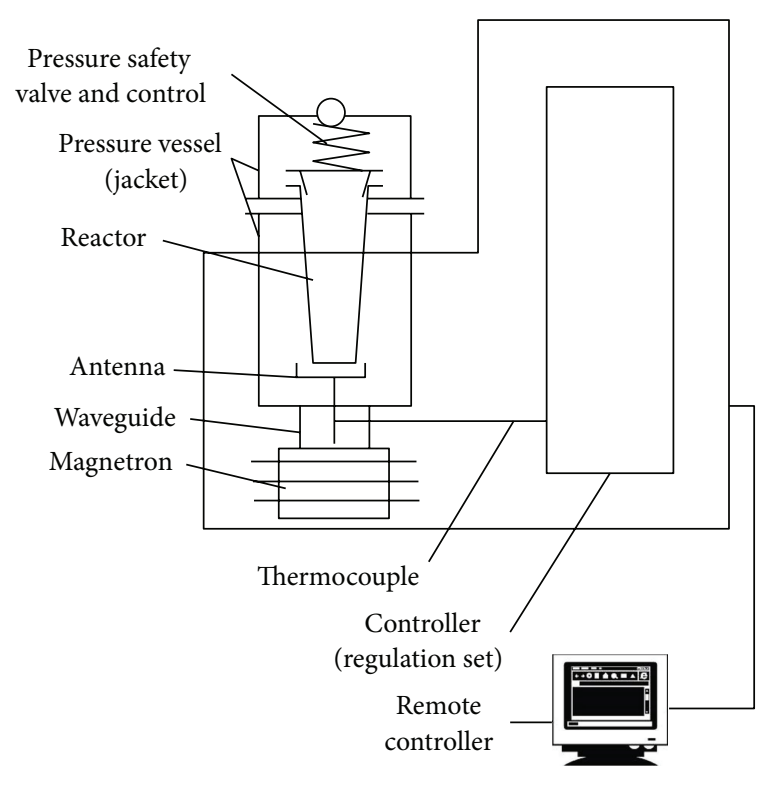

(c)

FIGURE 1: Magnum 02-02 ERTEC microwave reactor: (a) reactor photograph, (b) Teflon reaction container, and (c) reactor diagram [79].

TABLE 1: Water content in ethylene glycol and in the precursor with constant concentration of $\mathrm{Zn}\left(\mathrm{CH}_{3} \mathrm{COO}\right)_{2} \cdot 2 \mathrm{H}_{2} \mathrm{O}$, which was $0.3254 \mathrm{~mol} / \mathrm{dm}^{3}$ for all samples.

\begin{tabular}{lc}
\hline Sample & $\begin{array}{c}C p_{\mathrm{H}_{2} \mathrm{O}} \\
{[\mathrm{wt} . \%]}\end{array}$ \\
\hline Ethylene glycol, solvent & $0.27 \pm 0.01$ \\
$\mathrm{ZnO}(1 \%)$ & $1.01 \pm 0.04$ \\
$\mathrm{ZnO}(1.5 \%)$ & $1.41 \pm 0.07$ \\
$\mathrm{ZnO}(2 \%)$ & $1.89 \pm 0.11$ \\
$\mathrm{ZnO}(3 \%)$ & $2.93 \pm 0.13$ \\
$\mathrm{ZnO}(4 \%)$ & $3.89 \pm 0.11$ \\
\hline
\end{tabular}

isotherm equation [86], in accordance with ISO 9277:2010. Prior to performing measurements of density and specific surface area, the samples were subject to $2 \mathrm{~h}$ desorption in a desorption station (FlowPrep, 060 Micromeritics, USA), at temperature of $150^{\circ} \mathrm{C}$ with the flow of helium of $99.9999 \%$ purity. Based on the determined specific surface area and pycnometric density, the average size of particles defining their diameter was determined, with the assumption that all particles are spherical and identical [87]. The following equation was used for calculating the average particle size:

$$
D=\frac{N \cdot 1000}{\mathrm{SSA} \cdot \rho} .
$$

The above equation is for calculating the average particle size, where $D$ is average size (diameter) of particles [nm], $N$ is shape coefficient being 6 for the sphere $[88,89]$, SSA is specific surface area $\left[\mathrm{m}^{2} / \mathrm{g}\right]$, and $\rho$ is density $\left[\mathrm{g} / \mathrm{cm}^{3}\right]$.

2.6. Morphologic Characteristics and Energy Dispersive Spectrometry (EDS). The morphology of NPs was determined using the scanning electron microscopy (SEM) (ZEISS, ULTRA PLUS, Germany). Powder samples were coated with a thin carbon layer using the sputter coater (SCD 005/CEA 035, BAL-TEC, Switzerland). An internal laboratory measurement procedure was applied (P5.10, edition 6 of 26.08.2015).

The morphology of the nanopowder samples was examined using TEM-JEOL JEM2000EX and Titan Cubed 80-300. The TEM tests using the dark field (DF) and selected area electron diffraction (SAED) were conducted at $200 \mathrm{kV}$. Highresolution transmission electron microscopy (HRTEM) tests were conducted at $300 \mathrm{kV}$. The specimens for the TEM observations were prepared by dropping the ethanol particle dispersion, created by an ultrasonic technique, on a carbon film supported on a 300-mesh copper grid. TEM tests were used to determine the nanoparticle size distribution. The grain size histograms were obtained by considering a region of a sample having about 250 nanocrystals and approximating the shape of each nanocrystal by a sphere. The obtained histograms were fitted to lognormal distributions [90].

Samples of $\mathrm{ZnO}$ NPs for the EDS measurement were pressed to the form of pastilles with diameter of $5 \mathrm{~mm}$. The quantitative X-ray microanalysis was carried out using the EDS analyser (Quantax 400, Bruker, USA).

2.7. Water Content Analysis. The quantitative analysis of water in the precursor was carried out in accordance with the assumptions of the Karl Fischer method using the coulometric titration technique with the titrator (Cou-Lo AquaMAX KF, GR Scientific, Great Britain). An internal laboratory measurement procedure was applied. Liquid samples were introduced to the titration vessel using a glass syringe $(1 \mathrm{~mL})$ with a Luer type needle. An analytical scale was used for weight measurement (WAA 100/C/1, RADWAG, Poland). 


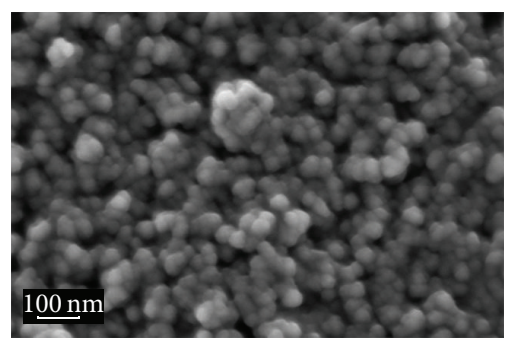

(a)

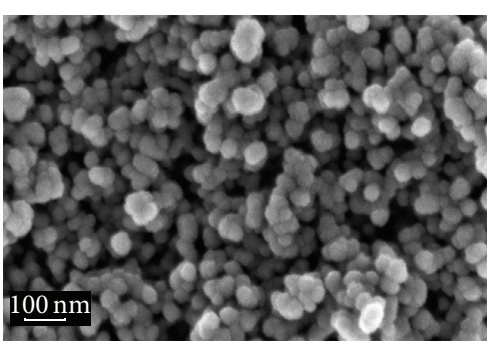

(b)

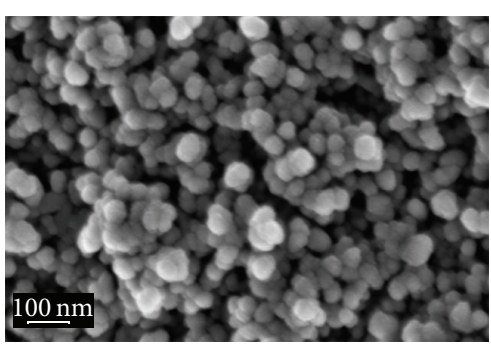

(c)

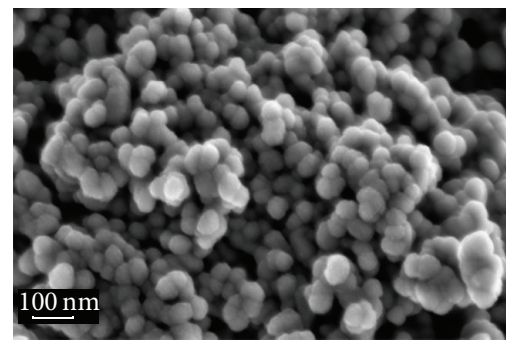

(d)

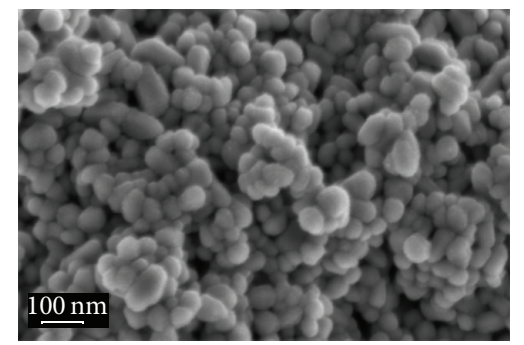

(e)

Figure 2: The SEM images of the $\mathrm{ZnO}$ nanoparticles with various water content in the precursor: (a) $1 \%$; (b) $1.5 \%$; (c) $2 \%$; (d) $3 \%$; (e) $4 \%$.

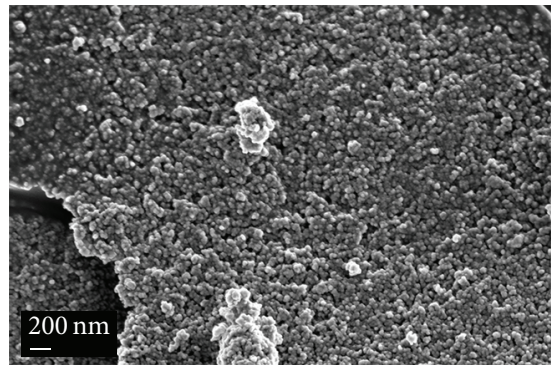

(a)

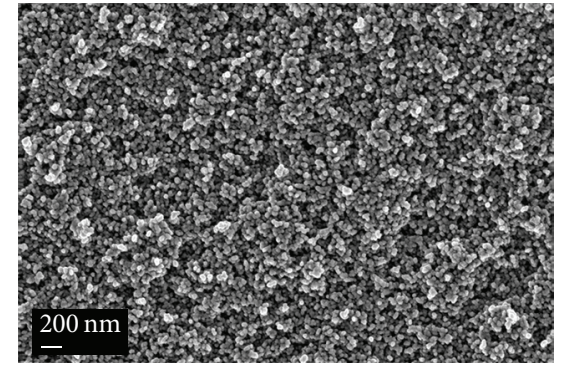

(b)

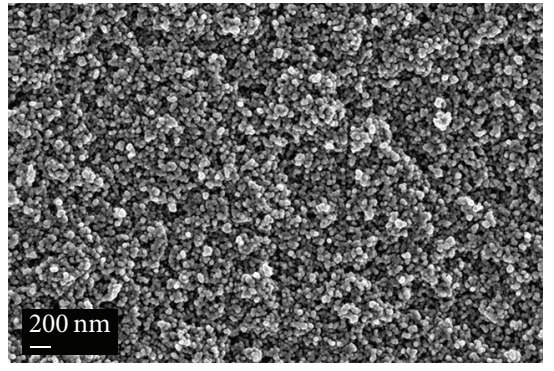

(c)

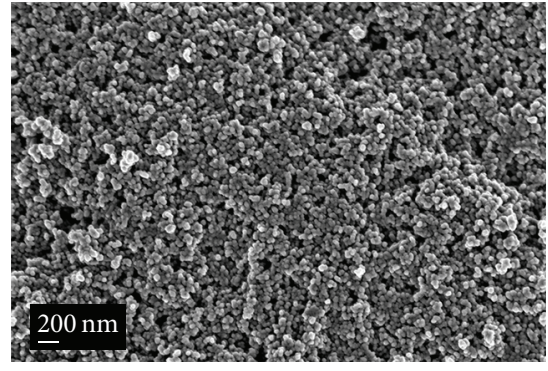

(d)

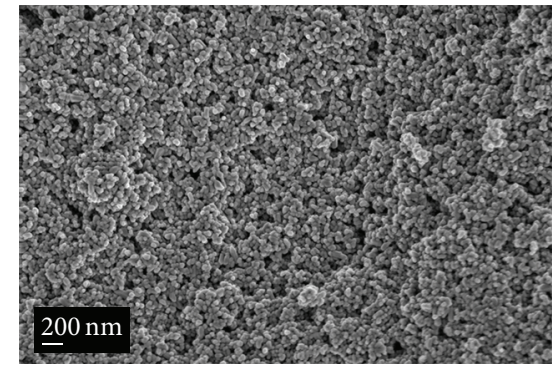

(e)

Figure 3: The SEM images of the $\mathrm{ZnO}$ nanoparticles with various water content in the precursor: (a) $1 \%$; (b) $1.5 \%$; (c) $2 \%$; (d) $3 \%$; (e) $4 \%$.

\section{Results and Discussion}

3.1. Morphology. Figures 2 and 3 present representative SEM images of $\mathrm{ZnO}$ NPs of all obtained powders. Figure 2 shows the homogeneous morphology and spherical shape of $\mathrm{ZnO}$ NPs. Figures 4 and 5 are TEM images of the obtained $\mathrm{ZnO}$ NPs. They show agglomerates/aggregates composed of homogeneous $\mathrm{ZnO}$ particles. It can be noticed in TEM images that a change in water content affects the size and shape of NPs. Figures 4 and 5 prove that the samples are composed of NPs with the spherical and hexagonal shape. In line with water content growth in the precursor, the shape of NPs gradually changes from spherical through elliptical to hexagonal (Figures 4 and 5). For 1\% water content in the precursor, the dominant population is NPs with the spherical shape (Figures 4, 5, and 6). NPs with the hexagonal shape prevail in the sample obtained from the precursor with $4 \%$ water content. Particle size between 15 and $40 \mathrm{~nm}$ was observed in SEM and TEM images for $1 \%$ water content, while for the samples of $\mathrm{ZnO}$ NPs with $4 \%$ water addition 


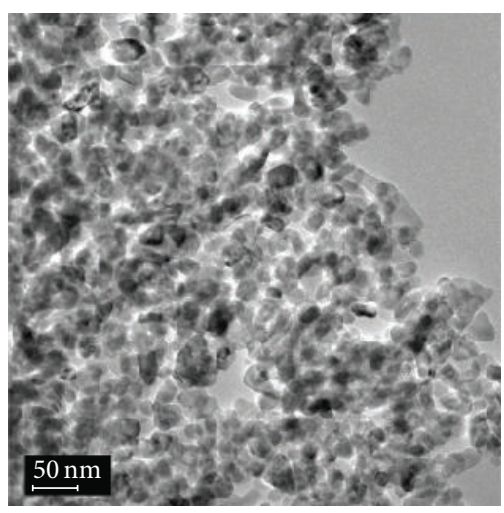

(a)

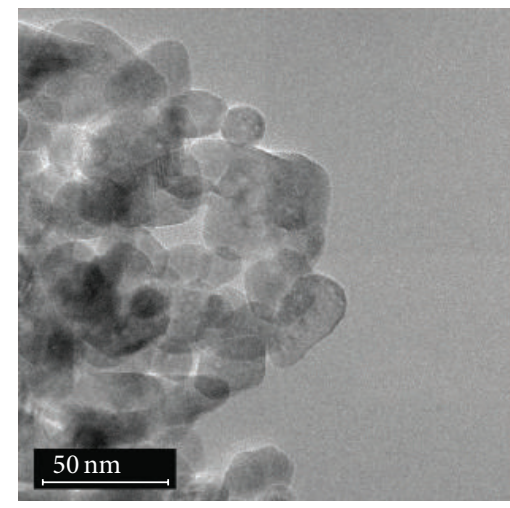

(b)

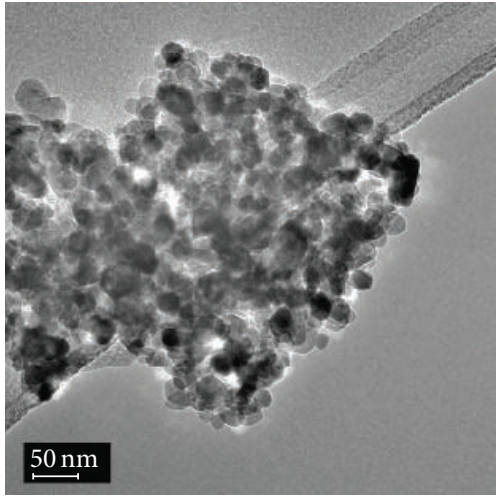

(c)

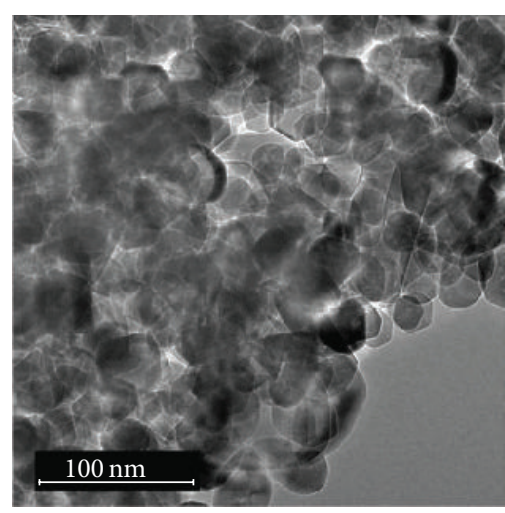

(d)

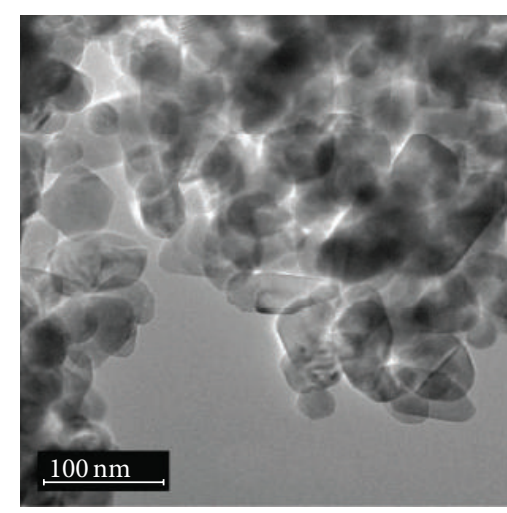

(e)

FIgURE 4: The TEM images of the $\mathrm{ZnO}$ nanoparticles with various water content in the precursor: (a) $1 \%$; (b) $1.5 \%$; (c) $2 \%$; (d) $3 \%$; (e) $4 \%$.

the particle size was between 20 and $100 \mathrm{~nm}$. Figure 6 shows schematically the effect, observed by us, of water content on the morphology of the nanoparticles. Based on the results we obtained, we can confirm that water exerts a very significant impact during the growth of $\mathrm{ZnO}$ crystals on their shape. A similar impact of water on the shape and size of the obtained $\mathrm{ZnO}$ NPs is described by other papers [43, 67, $69,71]$. The primary problems in obtaining ZnO NPs are the lack of simultaneous control over shape, size, and size distribution of particles. It is presumed that there are several competitive mechanisms of $\mathrm{ZnO}$ reactions, which occur in parallel and are very sensitive to a change in synthesis conditions and precursor preparation, which would explain obtaining diverse $\mathrm{ZnO}$ nanostructures in terms of shape and size [55].

3.2. Phase Composition. All diffraction peaks (Figure 7) can be well indexed to the hexagonal phase $\mathrm{ZnO}$ reported in JCPDS card number 36-1451 (Table 2), confirming that only nanocrystalline $\mathrm{ZnO}$ was detected, within the resolution of the XRD method. No characteristic diffraction peaks from unreacted substrates, $\mathrm{Zn}(\mathrm{OH})_{2}$, or other phases or impurities were observed, which are frequently seen in the hydrothermal synthesis of $\mathrm{ZnO}$. Figure 7 displays a noticeable difference between the widths of diffraction peaks of $\mathrm{ZnO}$ NPs samples. The higher the water content in the precursor, the narrower
TABLE 2: Standard JCPDS card of bulk $\mathrm{ZnO}$ with hexagonal structure (JCPDS number 36-1451).

\begin{tabular}{lclll}
\hline $2 \theta,\left(^{\circ}\right)$ & Intensity & $h$ & $k$ & $l$ \\
\hline 31.728 & 578 & 1 & 0 & 0 \\
34.400 & 442 & 0 & 0 & 2 \\
36.212 & 999 & 1 & 0 & 1 \\
47.494 & 229 & 1 & 0 & 2 \\
56.519 & 324 & 1 & 1 & 0 \\
62.803 & 276 & 1 & 0 & 3 \\
66.283 & 44 & 2 & 0 & 0 \\
67.866 & 243 & 1 & 1 & 2 \\
68.992 & 114 & 2 & 0 & 1 \\
72.516 & 19 & 0 & 0 & 4 \\
76.860 & 38 & 2 & 0 & 2 \\
81.315 & 19 & 1 & 0 & 4 \\
89.500 & 74 & 2 & 0 & 3 \\
\hline
\end{tabular}

the diffraction peaks observed and, at the same time, the greater the size of obtained $\mathrm{ZnO}$ crystallites.

No influence of the particle size on $a$ and $c$ lattice parameters was observed (Table 3, Figure 8). The $a$ and $c$ crystalline lattice parameters for $\mathrm{ZnO}$ assume the following values for $a$ from $3.2496 \AA$ to $3.2502 \AA$ and for $c$ from $5.2057 \AA$ 
TABLE 3: Lattice parameter of $\mathrm{ZnO}$ NPs.

\begin{tabular}{lcccc}
\hline Sample & \multicolumn{2}{c}{ Lattice parameter } & Ratio of lattice & $\begin{array}{c}\text { In hcp structure, ZnO, ratio of } \\
\text { lattice parameter } c / a\end{array}$ \\
\hline $\mathrm{ZnO}(1 \%)$ & $3.2502 \pm 0.0003$ & $5.2061 \pm 0.0004$ & $1.6018 \pm 0.0003$ & $1.6018 \pm 0.0003$ \\
$\mathrm{ZnO}(1.5 \%)$ & $3.2502 \pm 0.0003$ & $5.2061 \pm 0.0004$ & $1.6018 \pm 0.0003$ & 1.6330 \\
$\mathrm{ZnO}(2 \%)$ & $3.2499 \pm 0.0003$ & $5.2057 \pm 0.0004$ & $1.6020 \pm 0.0003$ & $1.6020 \pm 0.0003$ \\
$\mathrm{ZnO}(3 \%)$ & $3.2497 \pm 0.0003$ & $5.2059 \pm 0.0004$ & 1.6021 \\
$\mathrm{ZnO}(4 \%)$ & $3.2496 \pm 0.0003$ & $5.2059 \pm 0.0004$ & \\
$\mathrm{ZnO}(\mathrm{JCPDS}$ number 36-1451) & 3.2498 & 5.2066 & & \\
\hline
\end{tabular}

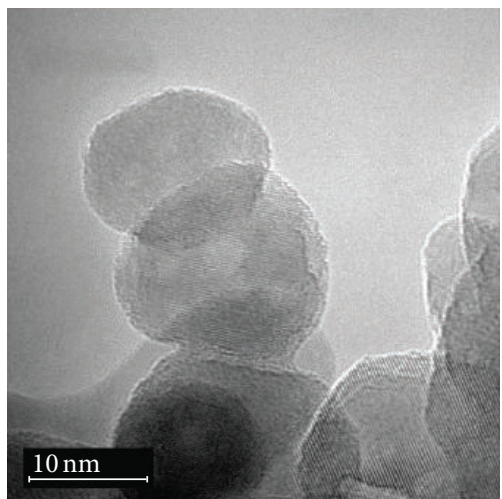

(a)

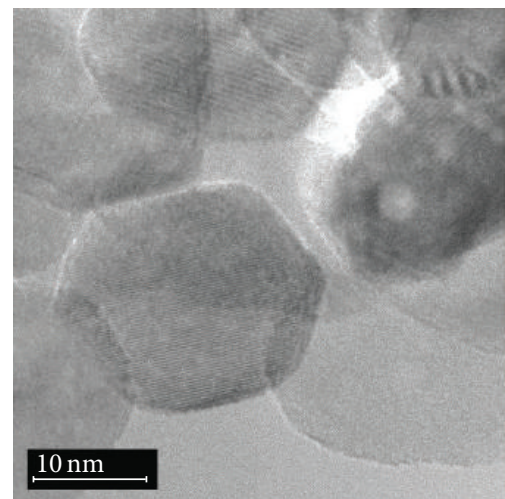

(b)

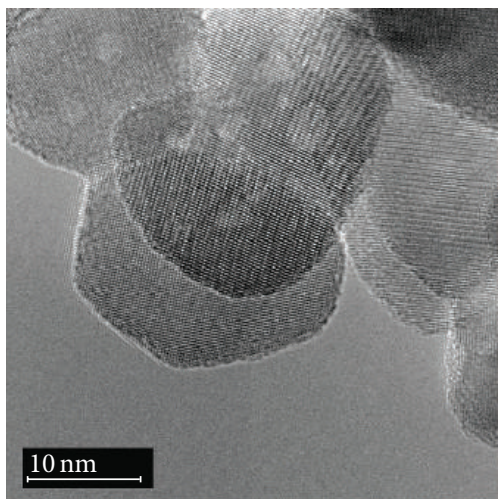

(c)

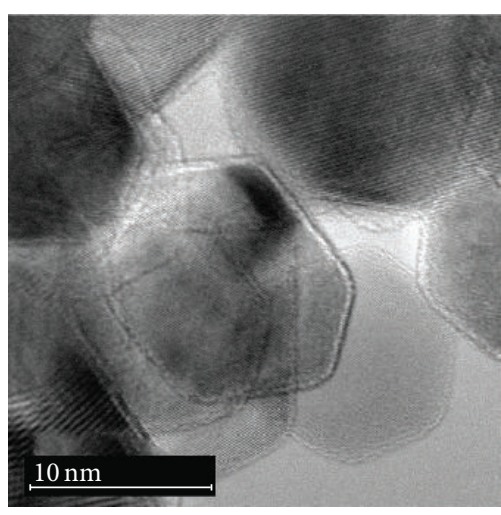

(d)

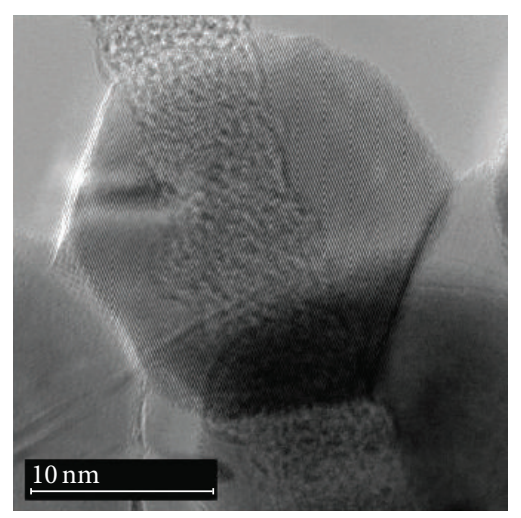

(e)

FIgure 5: The TEM images of the $\mathrm{ZnO}$ nanoparticles: (a) $1 \% \mathrm{H}_{2} \mathrm{O}$; (b) $1.5 \% \mathrm{H}_{2} \mathrm{O}$; (c) $2 \% \mathrm{H}_{2} \mathrm{O}$; (d) $3 \% \mathrm{H}_{2} \mathrm{O}$; (e) $4 \% \mathrm{H}_{2} \mathrm{O}$.

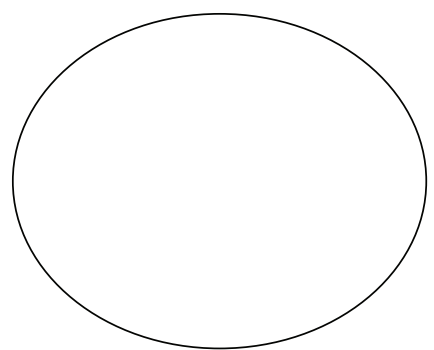

(a)

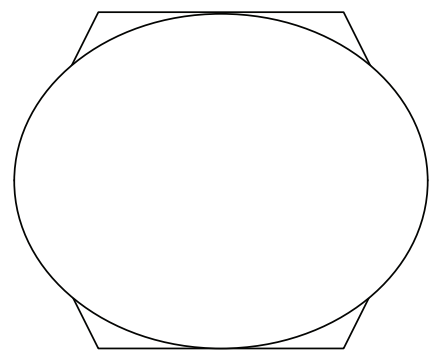

(b)

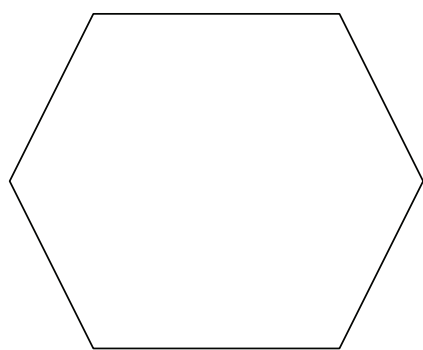

(c)

FIgure 6: Overview: shapes of $\mathrm{ZnO}$ NPs for samples: (a) $1 \% \mathrm{H}_{2} \mathrm{O}$; (b) $2 \% \mathrm{H}_{2} \mathrm{O}$; (c) $4 \% \mathrm{H}_{2} \mathrm{O}$. 
TABLE 4: Results of chemical analyses of $\mathrm{ZnO}$ nanopowders.

\begin{tabular}{lcccc}
\hline Sample & & $\mathrm{EDS}$ & & Stoichiometry of obtained ZnO \\
\hline $\mathrm{ZnO}(1 \%)$ & $51.26 \pm 0.27$ & $\mathrm{O}$ [value $\pm \sigma$, at. $\%$ ] & $\mathrm{Zn} / \mathrm{O}$ ratio [value $\pm \sigma]$ & $\mathrm{Zn}_{1} \mathrm{O}_{0.951}$ \\
$\mathrm{ZnO}(1.5 \%)$ & $51.22 \pm 0.09$ & $48.74 \pm 0.27$ & $1.05 \pm 0.02$ & $\mathrm{Zn}_{1} \mathrm{O}_{0.952}$ \\
$\mathrm{ZnO}(2 \%)$ & $51.46 \pm 1.03$ & $48.78 \pm 0.09$ & $1.05 \pm 0.01$ & $\mathrm{Zn}_{1} \mathrm{O}_{0.943}$ \\
$\mathrm{ZnO}(3 \%)$ & $51.46 \pm 0.03$ & $48.54 \pm 0.03$ & $1.06 \pm 0.05$ & $\mathrm{Zn}_{1} \mathrm{O}_{0.943}$ \\
$\mathrm{ZnO}(4 \%)$ & $51.48 \pm 0.33$ & $48.52 \pm 0.33$ & $1.06 \pm 0.01$ & $\mathrm{Zn}_{1} \mathrm{O}_{0.943}$ \\
\hline
\end{tabular}

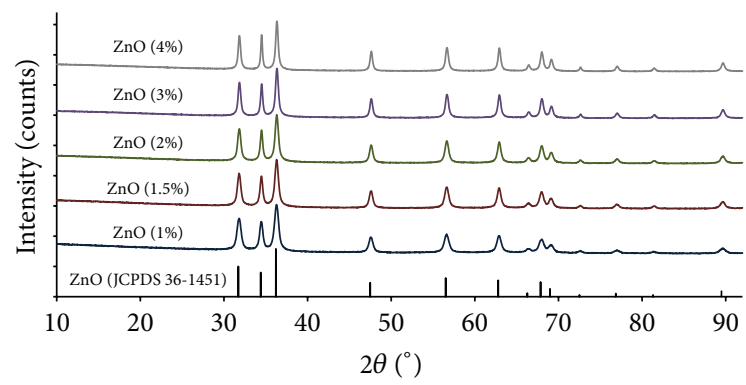

FIGURE 7: XRD pattern of $\mathrm{ZnO}$ nanoparticles and its comparison with the standard pattern of $\mathrm{ZnO}$ in wurtzite phase (JCPDS number 36-1451).

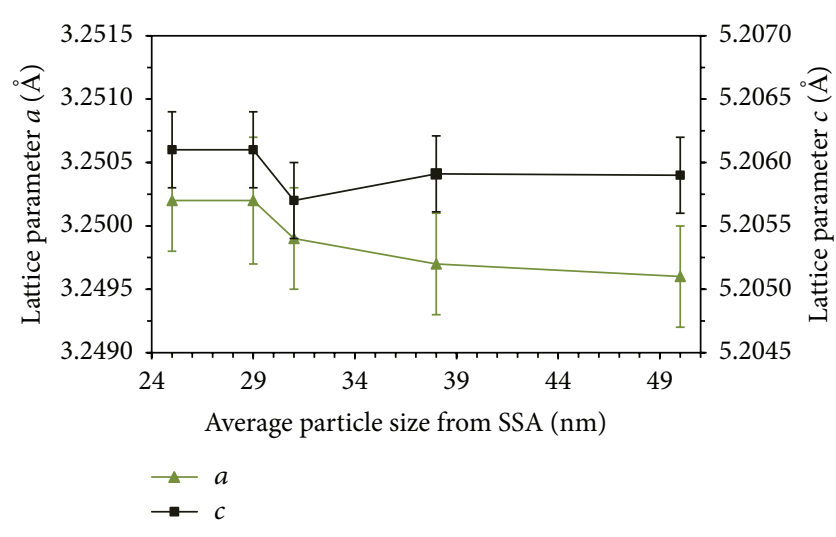

Figure 8: Lattice parameter of ZnO NPs.

to $5.2061 \AA$, where their $c / a$ ratio is circa 1.602 and is close to a close packed hexagonal structure $c / a=1.633$ [7]. The obtained results for $c / a$ reveal that a change in ZnO NPs size does not lead to a change in the proportions of dimensions of the unit cell (Table 3, Figure 8). However, a change in the crystallite dimension $d_{c} / d_{a}$ ratio was observed (Table 5), which indicates a reorientation of proportions of crystallite sizes and the shape from spherical to elliptical/hexagonal, which was confirmed also by TEM microscopic tests (Figures 4 and 5).

3.3. Density and Specific Surface Area. Theoretical density of $\mathrm{ZnO}$ is $5.61 \mathrm{~g} / \mathrm{cm}^{3}$. Pycnometric density of the obtained $\mathrm{ZnO}$ NPs ranged from $5.29 \mathrm{~g} / \mathrm{cm}^{3}$ to $5.43 \mathrm{~g} / \mathrm{cm}^{3}$ for the size range of NPs from $25 \mathrm{~nm}$ to $50 \mathrm{~nm}$ (Table 5). The observed correlation

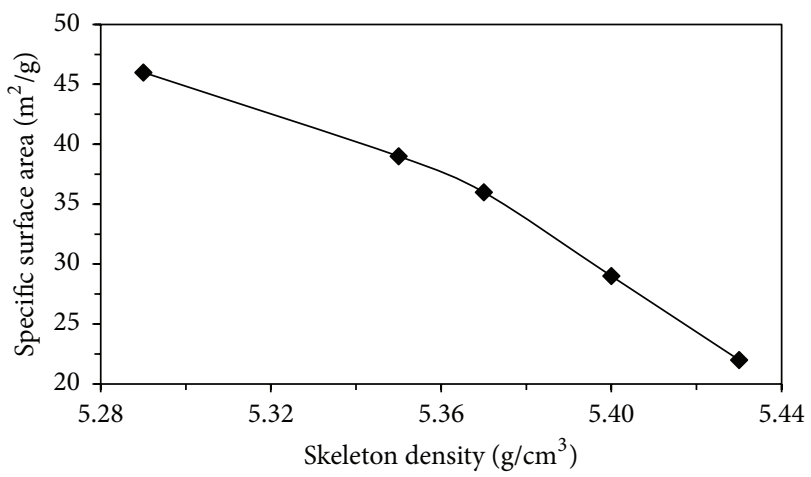

FIGURE 9: Correlations between specific surface area and density of $\mathrm{ZnO}$ NPs.

between the particle size and density is well known and explained by the influence of their size changes on

(i) quantity of amorphous phase, hydroxides, and crystalline $\mathrm{H}_{2} \mathrm{O}$ [91],

(ii) quantity of occurring surface defects [92],

(iii) quantity of defects of the crystalline lattice and nonstoichiometry of $\mathrm{ZnO}$ [93],

(iv) presence of impurities/doping [94].

Figure 9 shows a correlation between density and specific surface area of NPs. As already mentioned, it is understandable that in line with an increase in NPs size density increases and specific surface area decreases. For the smallest obtained NPs with particle size of $25 \mathrm{~nm}$, the specific surface area was $46 \mathrm{~m}^{2} / \mathrm{g}$, with their density being equal to $5.29 \mathrm{~g} / \mathrm{cm}^{3}$. For NPs sized $50 \mathrm{~nm}$, specific surface area amounted to $22 \mathrm{~m}^{2} / \mathrm{g}$, with their density being equal to $5.43 \mathrm{~g} / \mathrm{cm}^{3}$. The same correlation of the influence of particle size change on their density and specific surface area was observed in the case of $\mathrm{ZrO}_{2} \mathrm{NPs}$ and hydroxyapatite NPs [90, 91].

3.4. Chemical Composition. The analysis of the chemical composition was carried out by EDS method. The chemical composition of $\mathrm{ZnO}$ showed some nonstoichiometry (Table 4). Excess of zinc atoms, being circa 5-6 at.\% in relation to oxygen atoms, is noticeable. The XRD test did not reveal presence of foreign phases. Quantity of 5-6 at.\% of the foreign phase is at the limit of the diffractometric method detection. However, the tests of the chemical composition did not indicate presence of other atoms than zinc, oxygen, and carbon. Carbon was introduced to the samples through the coating process prior to the EDS measurement and could 
TABLE 5: Characteristic of the ZnO NPs samples.

\begin{tabular}{lccccccc}
\hline Sample & $\begin{array}{c}\text { Specific surface } \\
\text { area by gas } \\
\text { adsorption, } \\
a_{s} \pm \sigma\left(\mathrm{m}^{2} / \mathrm{g}\right)\end{array}$ & $\begin{array}{c}\text { Skeleton density } \\
\text { by gas } \\
\text { pycnometry, } \\
\rho_{s} \pm \sigma\left(\mathrm{g} / \mathrm{cm}^{3}\right)\end{array}$ & $\begin{array}{c}\text { Average particle } \\
\text { size from SSA } \\
\text { BET, } d \pm \sigma(\mathrm{nm})\end{array}$ & $\begin{array}{c}\text { Average crystallite } \\
\text { size from } \\
\text { Nanopowder XRD } \\
\text { Processor Demo, } \\
d \pm \sigma(\mathrm{nm})\end{array}$ & $\begin{array}{c}\text { Average } \\
\text { crystallite size, } \\
\text { Scherrer's } \\
\text { formula, based on } \\
\text { XRD, } d_{a}, d_{c}(\mathrm{~nm})\end{array}$ & $\begin{array}{c}\text { Ratio of average } \\
\text { crystallite size, } \\
\text { Scherrer's } \\
\text { formula, } d_{c} / d_{a}\end{array}$ & $\begin{array}{c}\text { Average particle } \\
\text { size from TEM, } \\
d \pm \sigma(\mathrm{nm})\end{array}$ \\
\hline $\mathrm{ZnO}(1 \%)$ & $46 \pm 1$ & $5.29 \pm 0.08$ & $25 \pm 1$ & $22 \pm 7$ & 18,23 & 1.278 & $19.8 \pm 0.3$ \\
$\mathrm{ZnO}(1.5 \%)$ & $39 \pm 1$ & $5.35 \pm 0.08$ & $29 \pm 1$ & $26 \pm 8$ & 23,29 & 1.261 & $24.6 \pm 0.3$ \\
$\mathrm{ZnO}(2 \%)$ & $36 \pm 1$ & $5.37 \pm 0.05$ & $31 \pm 1$ & $29 \pm 10$ & 24,33 & 1.375 & $24.8 \pm 0.3$ \\
$\mathrm{ZnO}(3 \%)$ & $29 \pm 1$ & $5.40 \pm 0.03$ & $38 \pm 2$ & $35 \pm 12$ & 30,39 & 1.300 & $28.1 \pm 0.3$ \\
$\mathrm{ZnO}(4 \%)$ & $22 \pm 1$ & $5.43 \pm 0.07$ & $50 \pm 3$ & $41 \pm 14$ & 33,48 & 1.455 & $65.7 \pm 0.3$ \\
\hline
\end{tabular}

contribute to a possible understatement of the results of the quantitative oxygen analysis. The \%at. $\mathrm{Zn} / \mathrm{O}$ ratio for all samples amounts to $\approx 1.05-1.06$. Nonstoichiometry of $\mathrm{ZnO}$ is well known and leads to the presence of point defects (interstitials and vacancies) and extended defects (threading/planar dislocations) [95]. Nonstoichiometry may be one of the reasons for the lower density of the obtained $\mathrm{ZnO}$ NPs than the theoretical density (Table 5). No influence of the changes in particle sizes on $\mathrm{ZnO}$ stoichiometry was observed (Table 5).

3.5. The Average Size and Size Distribution of NPs. The results are summarized in Table 5. The average size of $\mathrm{ZnO}$ NPs calculated based on the results of specific surface area and density ranged from $25 \mathrm{~nm}$ to $50 \mathrm{~nm}$ (Table 5). The average size calculated by this method is most representative in terms of quantity of the tested sample. The particle size determined based on XRD tests using the Scherrer method ranges from 23 to $48 \mathrm{~nm}$ (Table 5). On the other hand, the Nanopowder XRD Processor Demo [84] web application based on diffraction theory [83] permits obtaining the crystallite size distribution and average size. The average crystallite size between $22 \pm 7$ and $41 \pm 14 \mathrm{~nm}$ with a narrow size distribution was obtained (Figure 10). Figure 11 includes the distribution of $\mathrm{ZnO}$ sample sizes obtained based on TEM tests using the dark field technique. An increasing trend of the average particle size from $19.8 \pm 0.3$ to $65.7 \pm 0.3$ with a narrow size distribution is noticeable.

When comparing different methods of converting XRD results, Scherrer's formula, and Nanopowder XRD Processor Demo, similar results were obtained, falling within the standard deviation of the methods. The results of the XRD method calculated using Scherrer's formula coincide with the accuracy of $2 \mathrm{~nm}$ with the results of the method based on the results of surface area and density. The average size of particles of $\mathrm{ZnO}$ samples obtained by TEM method displays a certain discrepancy of results when compared with other methods. These discrepancies may be caused by the quantity of the tested sample. In the TEM method, merely 250 particles were analysed while in the case of other methods the particle quantities were in the order of billions. Another cause may be an assumption, for example, that a particle is spherical, which can be an error since Figure 7 reveals that the shape of a part of the particle population is often oval or hexagonal. The adopted assumptions of the methods generate a certain error

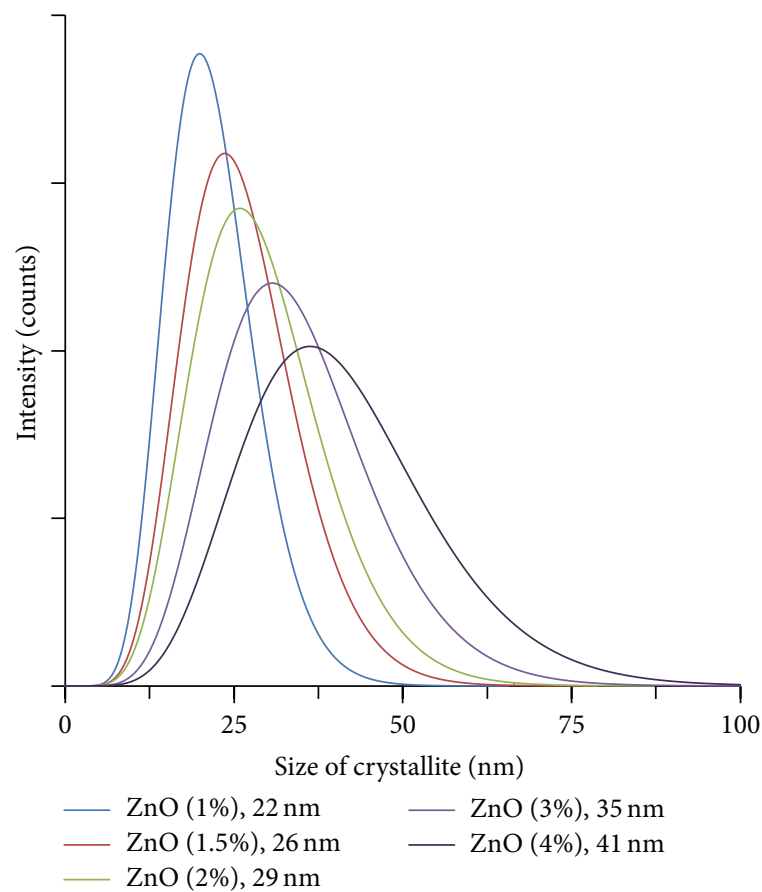

FIGURE 10: Crystallite size distribution obtained using Nanopowder

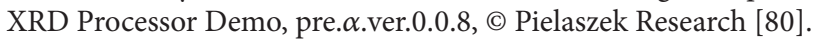

in the obtained results. However, currently it is technically impossible to individually take into account the actual shape of each particle while performing the calculations. Another cause of the discrepancies between the results of size distribution can be the fact that in the TEM methods particles are counted by their quantity while in XRD methods they are counted by their volume. Certain differences between the results of different measurement methods are always noticeable. The more the indirect method (algorithm) is used, the more the results will differ [96]. However, in general, all the used size characterisation methods lead to consistent results. Therefore, it can be implied that

(i) ZnO NPs are monocrystalline,

(ii) the size of ZnO NPs is equal to the crystallite size,

(iii) nanoparticles do not form aggregates. 


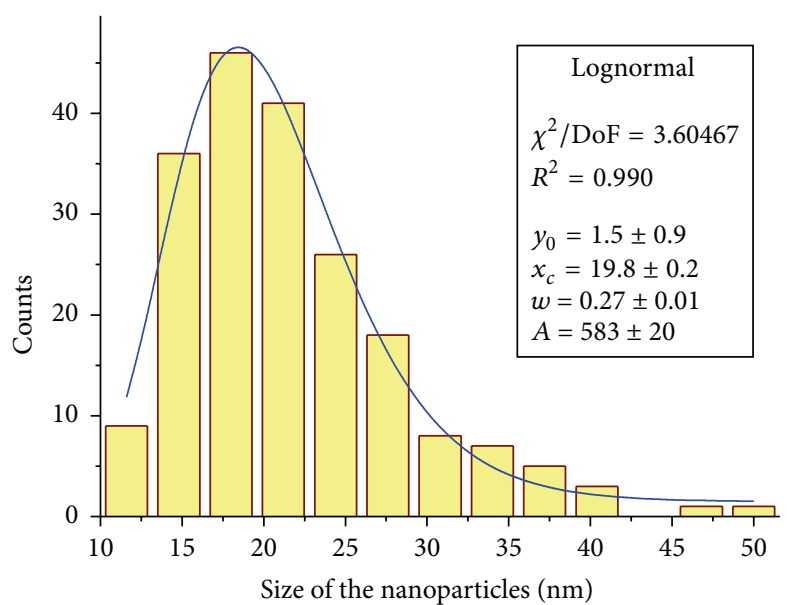

(a)

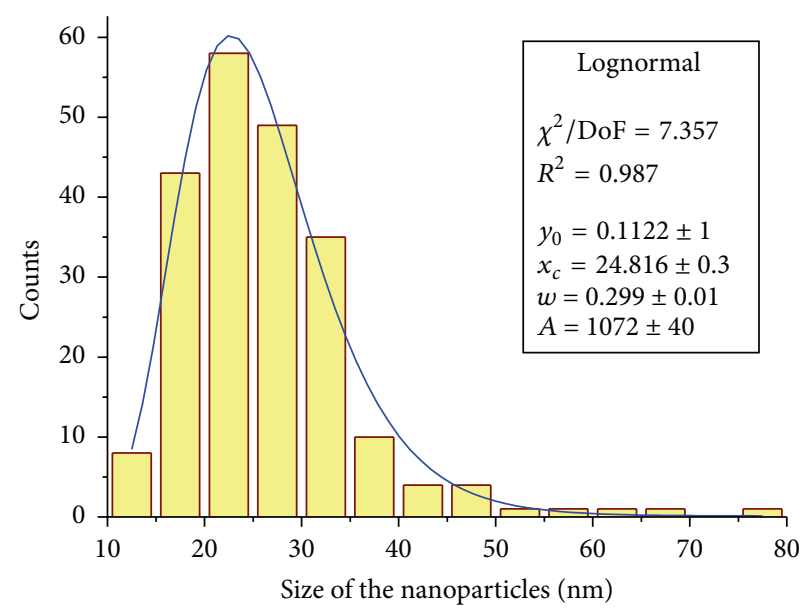

(c)

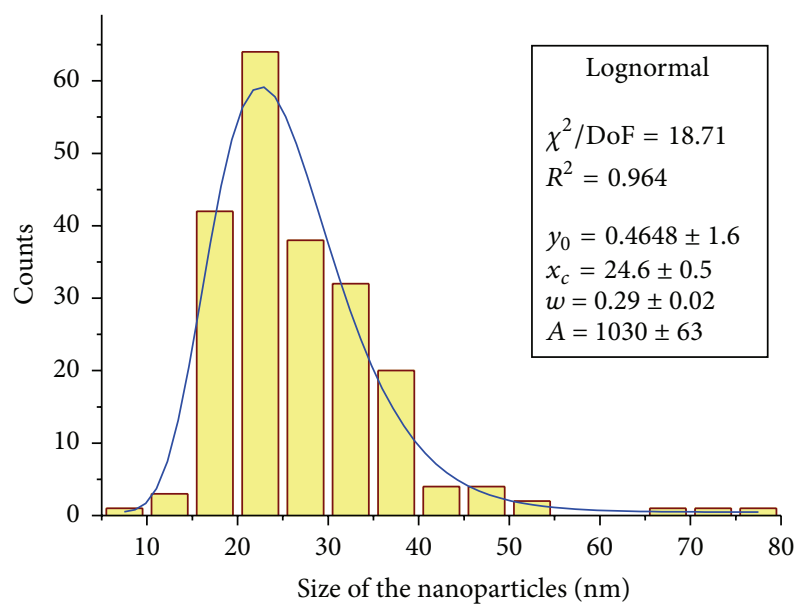

(b)

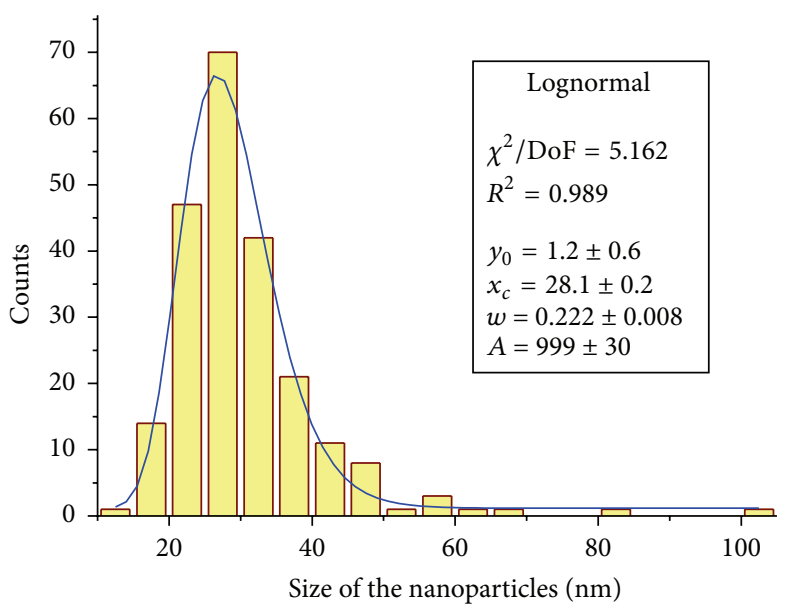

(d)

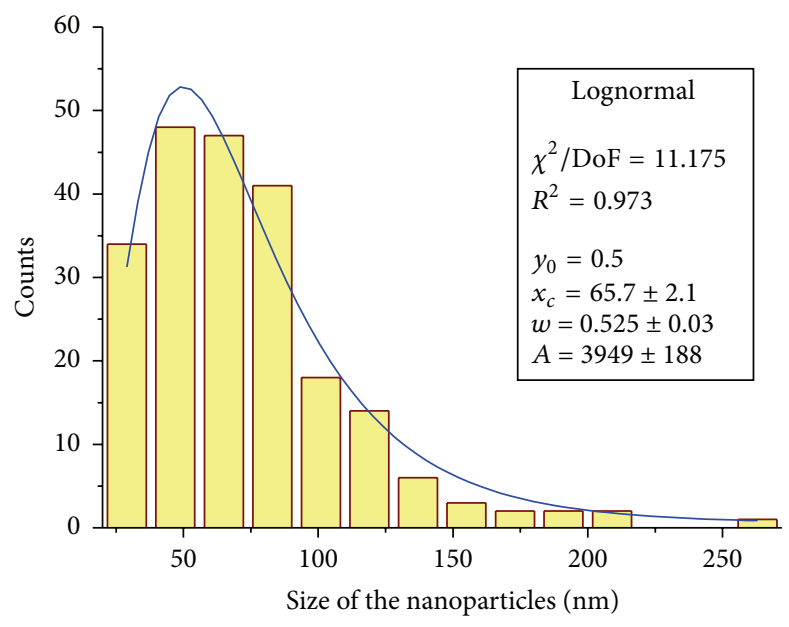

(e)

Figure 11: The histogram of the particle size distribution of $\mathrm{ZnO}$ : (a) $1 \% \mathrm{H}_{2} \mathrm{O}$, (b) $1.5 \% \mathrm{H}_{2} \mathrm{O}$, (c) $2 \% \mathrm{H}_{2} \mathrm{O}$, (d) $3 \% \mathrm{H}_{2} \mathrm{O}$, and (e) $4 \% \mathrm{H}_{2} \mathrm{O}$. 
Normally one $\mathrm{ZnO}$ particle is composed of several crystallites, which means that particle sizes are much greater than crystallite sizes. However, in our case, the synthesis in ethylene glycol results in producing ZnO NPs composed of monocrystallites.

The narrow size distribution of the obtained $\mathrm{ZnO}$ NPs and their homogeneous morphology result from the use of a microwave source of heating in the solvothermal synthesis. Microwave solvothermal syntheses are characterised by considerably shorter reaction times in comparison with standard heating methods. The sample is heated quickly and uniformly due to the direct particle heating through the energy of microwaves. This method is designated as endogenous or volumetric heating [59], which means that heat is generated within the whole volume of the sample and not transported through the reaction vessel walls from an external heat source. When comparing the method of microwave heated synthesis with standard heating, differences in parameters of the obtained products result from the pure thermal/kinetic effect and not from "specific" or "nonthermal" microwave effects in the preparation of nanomaterials [97]. In his paper, Schanche [98] showed the temperature profile after $60 \mathrm{sec}$ as affected by microwave irradiation compared to a treatment in an oil-bath. This is an excellent example indicating a small temperature gradient of samples heated by microwaves in comparison with the standard method. Reaction vessels of microwave reactors are primarily formed in Teflon, which is characterised by a low coefficient of thermal conductivity $(0.25 \mathrm{~W} /(\mathrm{m} \cdot \mathrm{K}))$ and acts as a thermal insulator, thanks to which a very small temperature gradient is achieved $[58,59]$. In our paper, through the use of a contactless heating method being microwave radiation and of a reaction vessel formed in a chemically inert material, we obtain $\mathrm{ZnO}$ NPs characterised by high chemical purity.

3.6. Programming the Size of $Z n O N P s$. The particle size dependence on water content is shown in Figure 12. For simplicity we assumed a linear dependence $y=a x+b$, where the values $a$ and $b$ are constants and $y$ means the average size of NPs, while $x$ is water concentration in the precursor. The calibration curve was determined using the linear regression based on experimental data. The following function formula was obtained: $y=8.23 x+16.27\left(R^{2}=0.9721\right)$, which enables programming the average size of $\mathrm{ZnO}$ particles for a given batch of the reagents used and constant parameters of synthesis. As already mentioned, the synthesis of $\mathrm{ZnO}$ NPs is sensitive to each change of the precursor caused, for example, by the composition and purity of reagents. In order to preserve the accuracy of particle size control when changing a batch of reagents, the operation of determining the calibration curve of $\mathrm{ZnO}$ NPs size should be performed again. Because both density and specific surface area depend on water content in the precursor (Figure 13), also calibration curves concerning these properties in the water content function can be determined. A calibration curve for NPs synthesis can be obtained for $\mathrm{ZnO}$ sizes up to $120 \mathrm{~nm}$ [99].

3.7. Synthesis Mechanism. The dependence of $\mathrm{ZnO}$ NPs size on water concentration in glycol can be explained by two phenomena:

(1) increased dissociation degree of $\mathrm{Zn}\left(\mathrm{CH}_{3} \mathrm{COO}\right)_{2}$. $2 \mathrm{H}_{2} \mathrm{O}$ as a result of increased concentration of $\mathrm{H}_{2} \mathrm{O}$ in ethylene glycol;

(2) increased size of zinc organic compound clusters from which $\mathrm{ZnO}$ NPs crystalize.

The probable mechanism of the reaction of microwave solvothermal synthesis of $\mathrm{ZnO} \mathrm{NPs}$ is presented by the following equations: (4) dissociation, (5) cluster growth, (6) crystallization, (7) esterification, and (8) abridged synthesis equation:

$$
\begin{aligned}
& \left(\mathrm{CH}_{3} \mathrm{COO}\right)_{2} \mathrm{Zn} \cdot 2 \mathrm{H}_{2} \mathrm{O} \stackrel{\mathrm{H}_{2} \mathrm{O}}{\longrightarrow}\left(\mathrm{CH}_{3} \mathrm{COO}\right) \mathrm{Zn}^{+} \cdot 2 \mathrm{H}_{2} \mathrm{O}+\mathrm{CH}_{3} \mathrm{COO}^{-} \\
& 5\left(\mathrm{CH}_{3} \mathrm{COO}\right) \mathrm{Zn}^{+} \cdot 2 \mathrm{H}_{2} \mathrm{O}+5 \mathrm{CH}_{3} \mathrm{COO}^{-} \stackrel{\text { T,P }}{\longrightarrow} \mathrm{Zn}_{5}(\mathrm{OH})_{8}\left(\mathrm{CH}_{3} \mathrm{COO}\right)_{2} \cdot 2 \mathrm{H}_{2} \mathrm{O}+8 \mathrm{CH}_{3} \mathrm{COOH} \\
& \mathrm{Zn}_{5}(\mathrm{OH})_{8}\left(\mathrm{CH}_{3} \mathrm{COO}\right)_{2} \cdot 2 \mathrm{H}_{2} \mathrm{O} \stackrel{\text { T,P }}{\longrightarrow} 5 \mathrm{ZnO}_{\downarrow}+2 \mathrm{CH}_{3} \mathrm{COOH}+5 \mathrm{H}_{2} \mathrm{O} \\
& \mathrm{CH}_{3} \mathrm{COOH}+\mathrm{C}_{2} \mathrm{H}_{4}(\mathrm{OH})_{2} \stackrel{\mathrm{T}, \mathrm{P}}{\longrightarrow} \mathrm{CH}_{3} \mathrm{COOC}_{2} \mathrm{H}_{4} \mathrm{OH}+\mathrm{H}_{2} \mathrm{O} \\
& \left(\mathrm{CH}_{3} \mathrm{COO}\right)_{2} \mathrm{Zn} \cdot 2 \mathrm{H}_{2} \mathrm{O} \stackrel{\mathrm{C}_{2} \mathrm{H}_{4}(\mathrm{OH})_{2}, \mathrm{H}_{2} \mathrm{O}, \mathrm{T}, \mathrm{P}}{\longrightarrow} \mathrm{ZnO}_{\downarrow}+2 \mathrm{H}_{2} \mathrm{O}+\mathrm{CH}_{3} \mathrm{COOC}_{2} \mathrm{H}_{4} \mathrm{OH}+\mathrm{CH}_{3} \mathrm{COOH}
\end{aligned}
$$

Two types of water are present in the precursor: structural water, which is bound chemically and is an integral part of $\mathrm{Zn}\left(\mathrm{CH}_{3} \mathrm{COO}\right)_{2} \cdot 2 \mathrm{H}_{2} \mathrm{O}$, and water present in ethylene glycol. Water present in ethylene glycol causes only dissociation of $\mathrm{Zn}\left(\mathrm{CH}_{3} \mathrm{COO}\right)_{2} \cdot 2 \mathrm{H}_{2} \mathrm{O}$ (4) and formation of clusters of zinc organic compounds $\mathrm{Zn}_{5}(\mathrm{OH})_{8}\left(\mathrm{CH}_{3} \mathrm{COO}\right)_{2} \cdot 2 \mathrm{H}_{2} \mathrm{O}$ (5). Acetic acid is a weak organic acid, so it was assumed that in the solution of glycol with water it would dissociate only to the form $\left(\mathrm{CH}_{3} \mathrm{COO}\right) \mathrm{Zn}^{+} \cdot 2 \mathrm{H}_{2} \mathrm{O}$. Water addition to the precursor results in increasing the quantity of the dissociated form $\left(\mathrm{CH}_{3} \mathrm{COO}\right) \mathrm{Zn}^{+} \cdot 2 \mathrm{H}_{2} \mathrm{O}$ and as a consequence in increasing the available building material necessary for cluster growth (4). 


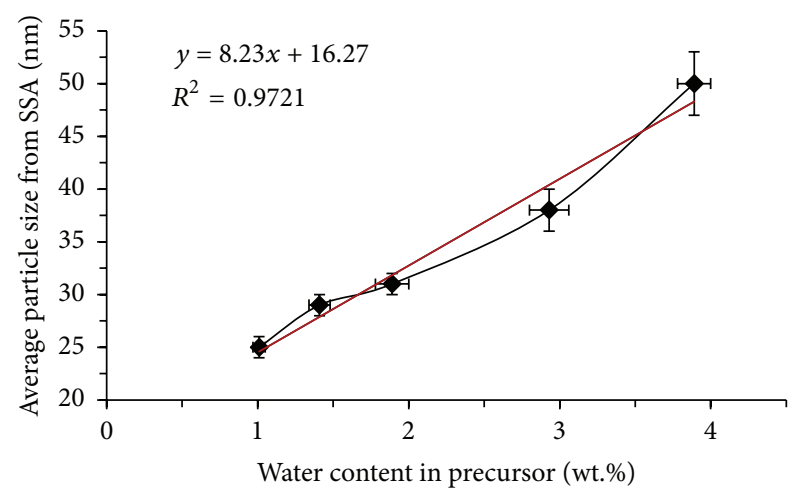

FIGURE 12: Calibration curve of average particle size in the function of water content in the precursor.

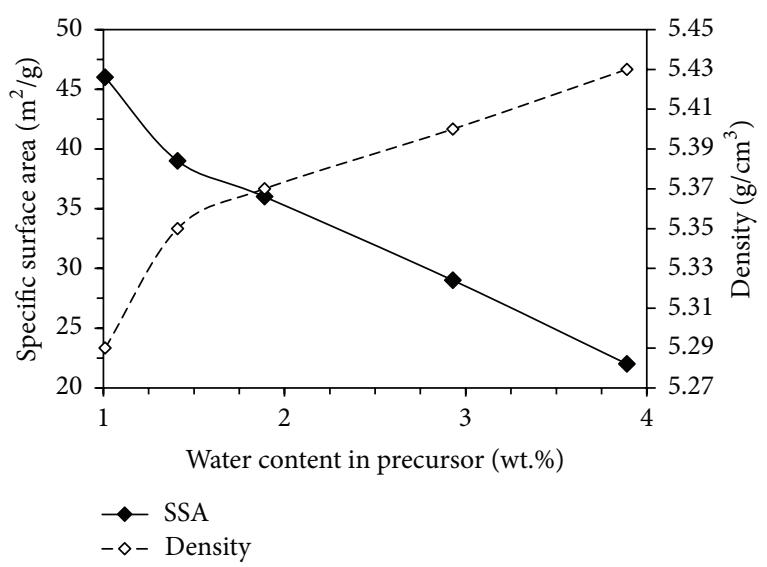

FIgURE 13: Value of specific surface area and density of ZnO NPs in the function of water content in the precursor.

Under influence of temperature, clusters grow and precipitate in the form of sediment. Particle size depends strictly on the size of the formed clusters, from which ZnO NPs crystalize under influence of temperature. Probably only structural water coming from $\mathrm{Zn}\left(\mathrm{CH}_{3} \mathrm{COO}\right)_{2} \cdot 2 \mathrm{H}_{2} \mathrm{O}$ takes part in the $\mathrm{ZnO}$ (4)-(6) synthesis reaction. In other words, the achieved control of NPs size by controlling water concentration in the precursor results from a changed growth dynamics of $\mathrm{Zn}_{5}(\mathrm{OH})_{8}\left(\mathrm{CH}_{3} \mathrm{COO}\right)_{2} \cdot 2 \mathrm{H}_{2} \mathrm{O}$ clusters. The primary reaction products apart from $\mathrm{ZnO}$ NPs are also water and acetic acid. Another possible chemical reaction being a consequence of $\mathrm{ZnO}$ synthesis is esterification reaction (7), in which acetic acid and ethylene glycol participate. The presence of esters in the postreaction suspended matter in the solvothermal reaction of zinc acetate in various alcohols was confirmed by Tonto et al. [100]. An undesirable side reaction, which may occur simultaneously with $\mathrm{ZnO}$ synthesis, is the reaction of degradation or polymerisation of ethylene glycol. Further research is required to confirm the role of $\mathrm{H}_{2} \mathrm{O}$ and synthesis mechanism in this case.

\section{Conclusions}

A method of controlling the average size of homogeneous $\mathrm{ZnO}$ NPs ranging from 25 to $50 \mathrm{~nm}$ with a narrow size distribution was developed. Zinc acetate dissolved in ethylene glycol with water addition was used as the precursor of microwave solvothermal synthesis. It was found that an increase in water content in ethylene glycol in the MSS led to an increase in the size of $\mathrm{ZnO}$ NPs. That result was interpreted as follows: water addition increases the dissociation degree of $\mathrm{Zn}\left(\mathrm{CH}_{3} \mathrm{COO}\right)_{2} \cdot 2 \mathrm{H}_{2} \mathrm{O}$, which leads to an increase in the size of the forming clusters of zinc organic compounds, from which $\mathrm{ZnO}$ NPs crystalize under influence of temperature. The morphology and density of the NPs depend on their size. ZnO NPs were characterised by homogeneous morphology. The shape changed from spherical to hexagonal in line with the increase in the nanoparticle size. The method of nanoparticle size control, discovered by us, may be used for optimising $\mathrm{ZnO}$ properties in specific applications.

\section{Competing Interests}

The authors declare that there are no competing interests regarding the publication of this paper.

\section{Acknowledgments}

The work reported here was conducted in the Shyman Project, Grant Agreement no. 280983 (2012-2016), under the 7th Framework Programme of the European Commission, coordinated by E. Lester (The University of Nottingham, United Kingdom, http://www.shyman.eu). The research subject was carried out with the use of equipment funded by the project CePT, reference POIG.02.02.00-14-024/08, financed by the European Regional Development Fund within the Operational Programme "Innovative Economy" for 20072013. HRTEM measurements have been carried out in the IF PAN within the project "Analytical High Resolution Transmission Electron Microscope for Nanoscience, Nanotechnology And Spintronics" number POIG.02.01-00-14-032/08. The authors would like also to thank J. Mizeracki, A. Presz, and S. Kuśnieruk from the Institute of High Pressure Physics of the Polish Academy of Sciences.

\section{References}

[1] M. Loos, "Chapter 1-nanoscience and nanotechnology," in Carbon Nanotube Reinforced Composites: CNR Polymer Science and Technology, pp. 1-36, 2015.

[2] O. L. Stroyuk, V. M. Dzhagan, V. V. Shvalagin, and S. Y. Kuchmiy, "Size-dependent optical properties of colloidal $\mathrm{ZnO}$ nanoparticles charged by photoexcitation," The Journal of Physical Chemistry C, vol. 114, no. 1, pp. 220-225, 2010.

[3] M. E. Vance, T. Kuiken, E. P. Vejerano et al., "Nanotechnology in the real world: redeveloping the nanomaterial consumer products inventory," Beilstein Journal of Nanotechnology, vol. 6, no. 1, pp. 1769-1780, 2015.

[4] J. J. Ramsden, "Applied nanotechnology," in A Volume in Micro and Nano Technologies, pp. 49-60, Elsevier, New York, NY, USA, 2014.

[5] Future Markets, Nanoparticles, and Zinc Oxide, The Global Market, 2nd edition, 2014. 
[6] D. Segets, J. Gradl, R. K. Taylor, V. Vassilev, and W. Peukert, "Analysis of optical absorbance spectra for the determination of $\mathrm{ZnO}$ nanoparticle size distribution, solubility, and surface energy," ACS Nano, vol. 3, no. 7, pp. 1703-1710, 2009.

[7] Ü. Özgür, Y. I. Alivov, C. Liu et al., "A comprehensive review of ZnO materials and devices," Journal of Applied Physics, vol. 98, no. 4, Article ID 041301, pp. 1-103, 2005.

[8] A. Ashrafi and C. Jagadish, "Review of zincblende ZnO: stability of metastable ZnO phases," Journal of Applied Physics, vol. 102, no. 7, Article ID 071101, 2007.

[9] E. Bacaksiz, M. Parlak, M. Tomakin, A. Özçelik, M. Karakiz, and M. Altunbaş, "The effects of zinc nitrate, zinc acetate and zinc chloride precursors on investigation of structural and optical properties of $\mathrm{ZnO}$ thin films," Journal of Alloys and Compounds, vol. 466, no. 1-2, pp. 447-450, 2008.

[10] Ü. Ozgur, D. Hofstetter, and H. Morkoç, "ZnO devices and applications: a review of current status and future prospects," Proceedings of the IEEE, vol. 98, no. 7, pp. 1255-1268, 2010.

[11] A. B. Djurišić, A. M. C. Ng, and X. Y. Chen, "ZnO nanostructures for optoelectronics: material properties and device applications," Progress in Quantum Electronics, vol. 34, no. 4, pp. 191-259, 2010.

[12] M. Willander, Q. X. Zhao, Q.-H. Hu et al., "Fundamentals and properties of zinc oxide nanostructures: optical and sensing applications," Superlattices and Microstructures, vol. 43, no. 4, pp. 352-361, 2008.

[13] M. A. Mitchnick, D. Fairhurst, and S. R. Pinnell, "Microfine zinc oxide (Z-Cote) as a photostable UVA/UVB sunblock agent," Journal of the American Academy of Dermatology, vol. 40, no. 1, pp. 85-90, 1999.

[14] L. Z. Kou, W. L. Guo, and C. Li, "Piezoelectricity of ZnO and its nanostructures," in Proceedings of the Symposium on Piezoelectricity, Acoustic Waves, and Device Applications (SPAWDA '08), pp. 354-359, Nanjing, China, December 2008.

[15] Z. L. Wang, "Novel nanostructures of $\mathrm{ZnO}$ for nanoscale photonics, optoelectronics, piezoelectricity, and sensing," Applied Physics A, vol. 88, no. 1, pp. 7-15, 2007.

[16] L. Schmidt-Mende and J. L. MacManus-Driscoll, "ZnOnanostructures, defects, and devices," Materials Today, vol. 10, no. 5, pp. 40-48, 2007.

[17] R. Kumar, O. Al-Dossary, G. Kumar, and A. Umar, "Zinc oxide nanostructures for $\mathrm{NO}_{2}$ gas-sensor applications: a review," Nano-Micro Letters, vol. 7, no. 2, pp. 97-120, 2015.

[18] P. S. Shewale, Y. S. Yu, J. H. Kim, C. R. Bobade, and M. D. Uplane, " $\mathrm{H}_{2} \mathrm{~S}$ gas sensitive $\mathrm{Sn}$-doped $\mathrm{ZnO}$ thin films: synthesis and characterization," Journal of Analytical and Applied Pyrolysis, vol. 112, pp. 348-356, 2015.

[19] S. K. Gupta, A. Joshi, and M. Kaur, "Development of gas sensors using ZnO nanostructures," Journal of Chemical Sciences, vol. 122, no. 1, pp. 57-62, 2010.

[20] V. R. Shinde, T. P. Gujar, C. D. Lokhande, R. S. Mane, and S.H. Han, "Development of morphological dependent chemically deposited nanocrystalline $\mathrm{ZnO}$ films for liquefied petroleum gas (LPG) sensor," Sensors and Actuators B: Chemical, vol. 123, no. 2, pp. 882-887, 2007.

[21] C. Dighavkar, "Characterization of nanosized zinc oxide based ammonia gas sensor," Archives of Applied Science Research, vol. 5, pp. 96-101, 2013.

[22] P. Rai, W.-K. Kwak, and Y.-T. Yu, "Solvothermal synthesis of $\mathrm{ZnO}$ nanostructures and their morphology-dependent gassensing properties," ACS Applied Materials and Interfaces, vol. 5, no. 8, pp. 3026-3032, 2013.
[23] E. Dilonardo, M. Penza, M. Alvisi et al., "Evaluation of gassensing properties of $\mathrm{ZnO}$ nanostructures electrochemically doped with Au nanophases," Beilstein Journal of Nanotechnology, vol. 7, pp. 22-31, 2016.

[24] M. Yin, M. Liu, and S. Liu, "Development of an alcohol sensor based on $\mathrm{ZnO}$ nanorods synthesized using a scalable solvothermal method," Sensors and Actuators B: Chemical, vol. 185, pp. 735-742, 2013.

[25] A. Sirelkhatim, S. Mahmud, A. Seeni et al., "Review on zinc oxide nanoparticles: antibacterial activity and toxicity mechanism," Nano-Micro Letters, vol. 7, no. 3, pp. 219-242, 2015.

[26] Y. Zhang, T. R. Nayak, H. Hong, and W. Cai, "Biomedical applications of zinc oxide nanomaterials," Current Molecular Medicine, vol. 13, no. 10, pp. 1633-1645, 2013.

[27] C. Jaqadish and S. J. Pearton, Zinc Oxide Bulk, Thin Films and Nanostructures, Elsevier, 2006.

[28] T. Yoshida, D. Komatsu, N. Shimokawa, and H. Minoura, "Mechanism of cathodic electrodeposition of zinc oxide thin films from aqueous zinc nitrate baths," Thin Solid Films, vol. 451452, pp. 166-169, 2004.

[29] F. Wang, R. Liu, A. Pan et al., "The optical properties of $\mathrm{ZnO}$ sheets electrodeposited on ITO glass," Materials Letters, vol. 61, no. 10, pp. 2000-2003, 2007.

[30] X. D. Gao, X. M. Li, and W. D. Yu, "Rapid preparation, characterization, and photoluminescence of $\mathrm{ZnO}$ films by a novel chemical method," Materials Research Bulletin, vol. 40, no. 7, pp. 1104-1111, 2005.

[31] V. R. Shinde, T. P. Gujar, and C. D. Lokhande, "Studies on growth of $\mathrm{ZnO}$ thin films by a novel chemical method," Solar Energy Materials \& Solar Cells, vol. 91, no. 12, pp. 1055-1061, 2007.

[32] J. Wojnarowicz, S. Kusnieruk, T. Chudoba et al., "Paramagnetism of cobalt-doped $\mathrm{ZnO}$ nanoparticles obtained by microwave solvothermal synthesis," Beilstein Journal of Nanotechnology, vol. 6, pp. 1957-1969, 2015.

[33] J. Wojnarowicz, R. Mukhovskyi, E. Pietrzykowska, S. Kusnieruk, J. Mizeracki, and W. Lojkowski, "Microwave solvothermal synthesis and characterization of manganese-doped $\mathrm{ZnO}$ nanoparticles," Beilstein Journal of Nanotechnology, vol. 7, pp. 721-732, 2016.

[34] S. J. Pearton, D. P. Norton, K. Ip, Y. W. Heo, and T. Steiner, "Recent progress in processing and properties of $\mathrm{ZnO}$," Superlattices and Microstructures, vol. 34, no. 1-2, pp. 3-32, 2003.

[35] Z. Jiang, T. Xiao, V. L. Kuznetsov, and P. P. Edwards, “Turning carbon dioxide into fuel," Philosophical Transactions of the Royal Society A, vol. 368, no. 1923, pp. 3343-3364, 2010.

[36] J. Zhang, C. Wang, R. Chowdhury, and S. Adhikari, "Sizeand temperature-dependent piezoelectric properties of gallium nitride nanowires," Scripta Materialia, vol. 68, no. 8, pp. 627630, 2013.

[37] S. Wang, Z. Cui, and Y. Xue, "Size-dependent thermodynamic properties of the reaction of Nano- $\mathrm{ZnO}$ with benzoic acid," Nano, vol. 10, Article ID 1550104, 7 pages, 2015.

[38] X. F. Wang, Y. L. Fang, T. L. Li, and F. J. Wang, "Sizedependence of photoluminescence property of $\mathrm{ZnO}$ nanoparticles," Advanced Materials Research, vol. 887-888, pp. 143-146, 2014.

[39] W. Promnopas, T. Thongtem, and S. Thongtem, "Effect of microwave power on energy gap of $\mathrm{ZnO}$ nanoparticles synthesized by microwaving through aqueous solutions," Superlattices and Microstructures, vol. 78, pp. 71-78, 2015. 
[40] L. Irimpan, V. P. N. Nampoori, P. Radhakrishnan, B. Krishnan, and A. Deepthy, "Size-dependent enhancement of nonlinear optical properties in nanocolloids of ZnO," Journal of Applied Physics, vol. 103, no. 3, Article ID 033105, 2008.

[41] S. Lopes, F. Ribeiro, J. Wojnarowicz et al., "Zinc oxide nanoparticles toxicity to Daphnia magna: size-dependent effects and dissolution," Environmental Toxicology and Chemistry, vol. 33, no. 1, pp. 190-198, 2014.

[42] L. R. Heggelund, M. Diez-Ortiz, S. Lofts et al., "Soil pH effects on the comparative toxicity of dissolved zinc, non-nano and nano $\mathrm{ZnO}$ to the earthworm Eisenia fetida," Nanotoxicology, vol. 8, no. 5, pp. 559-572, 2014.

[43] S. Lee, S. Jeong, D. Kim, S. Hwang, M. Jeon, and J. Moon, “ZnO nanoparticles with controlled shapes and sizes prepared using a simple polyol synthesis," Superlattices and Microstructures, vol. 43 , no. 4, pp. 330-339, 2008.

[44] N. Talebian, S. M. Amininezhad, and M. Doudi, "Controllable synthesis of $\mathrm{ZnO}$ nanoparticles and their morphologydependent antibacterial and optical properties," Journal of Photochemistry and Photobiology B: Biology, vol. 120, pp. 66-73, 2013.

[45] P. Zhu, J. Zhang, Z. Wu, and Z. Zhang, "Microwave-assisted synthesis of various $\mathrm{ZnO}$ hierarchical nanostructures: effects of heating parameters of microwave oven," Crystal Growth and Design, vol. 8, no. 9, pp. 3148-3153, 2008.

[46] P. X. Gao, Y. Ding, and Z. L. Wang, "Crystallographic orientation-aligned $\mathrm{ZnO}$ nanorods grown by a tin catalyst," Nano Letters, vol. 3, no. 9, pp. 1315-1320, 2003.

[47] X. Y. Kong, Y. Ding, R. S. Yang, and Z. L. Wang, "Single-crystal nanorings formed by epitaxial self-coiling of polar nanobelts," Science, vol. 303, no. 5662, pp. 1348-1351, 2004.

[48] J. Zhang, L. Sun, C. Liao, and C. Yan, "A simple route towards tubular ZnO," Chemical Communications, no. 3, pp. 262-263, 2002.

[49] Y. Zhang, H. Jia, X. Luo, X. Chen, D. Yu, and R. Wang, "Synthesis, microstructure, and growth mechanism of dendrite ZnO nanowires," Journal of Physical Chemistry B, vol. 107, no. 33, pp. 8289-8293, 2003.

[50] X. Y. Kong and Z. L. Wang, "Spontaneous polarizationinduced nanohelixes, nanosprings, and nanorings of piezoelectric nanobelts," Nano Letters, vol. 3, no. 12, pp. 1625-1631, 2003.

[51] P. X. Gao and Z. L. Wang, "Mesoporous polyhedral cages and shells formed by textured self-assembly of $\mathrm{ZnO}$ nanocrystals," Journal of the American Chemical Society, vol. 125, no. 37, pp. 11299-11305, 2003.

[52] Ž. Petrovića, M. Ristića, S. Musića, and M. Fabiánb, "Nano/microstructure and optical properties of $\mathrm{ZnO}$ particles precipitated from zinc acetylacetonate," Journal of Molecular Structure, vol. 1090, pp. 121-128, 2015.

[53] A.-Q. Zhang, L. Zhang, L. Sui, D.-J. Qian, and M. Chen, "Morphology-controllable synthesis of $\mathrm{ZnO}$ nano-/microstructures by a solvothermal process in ethanol solution," Crystal Research and Technology, vol. 48, no. 11, pp. 947-955, 2013.

[54] M. Jitianu and D. V. Goia, "Zinc oxide colloids with controlled size, shape, and structure," Journal of Colloid and Interface Science, vol. 309, no. 1, pp. 78-85, 2007.

[55] A. Kołodziejczak-Radzimska and T. Jesionowski, "Zinc oxidefrom synthesis to application: a review," Materials, vol. 7, no. 4, pp. 2833-2881, 2014.
[56] K. Byrappa and T. Adschiri, "Hydrothermal technology for nanotechnology," Progress in Crystal Growth and Characterization of Materials, vol. 53, no. 2, pp. 117-166, 2007.

[57] G. J. Demazeau, "Solvothermal reactions: an original route for the synthesis of novel materials," Journal of Materials Science, vol. 43, no. 7, pp. 2104-2114, 2008.

[58] W. Lojkowski, C. Leonelli, T. Chudoba, J. Wojnarowicz, A. Majcher, and A. Mazurkiewicz, "High-energy-low-temperature technologies for the synthesis of nanoparticles: microwaves and high pressure," Inorganics, vol. 2, no. 4, pp. 606-619, 2014.

[59] A. Majcher, J. Wiejak, J. Przybylski, T. Chudoba, and J. Wojnarowicz, "A novel reactor for microwave hydrothermal scaleup nanopowder synthesis," International Journal of Chemical Reactor Engineering, vol. 11, no. 1, pp. 361-368, 2013.

[60] P. W. Dunne, A. S. Munn, C. L. Starkey, and E. H. Lester, "The sequential continuous-flow hydrothermal synthesis of molybdenum disulphide," Chemical Communications, vol. 51, no. 19, pp. 4048-4050, 2015.

[61] P. W. Dunne, C. L. Starkey, A. S. Munn et al., "Benchand pilot-scale continuous-flow hydrothermal production of barium strontium titanate nanopowders," Chemical Engineering Journal, vol. 289, pp. 433-441, 2016.

[62] P. W. Dunne, A. S. Munn, C. L. Starkey, T. A. Huddle, and E. H. Lester, "Continuous-flow hydrothermal synthesis for the production of inorganic nanomaterials," Philosophical Transactions of the Royal Society A: Mathematical, Physical and Engineering Sciences, vol. 373, no. 2057, Article ID 20150015, 2015.

[63] M. Gimeno-Fabra, F. Hild, P. W. Dunne et al., "Continuous synthesis of dispersant-coated hydroxyapatite plates," CrystEngComm, vol. 17, no. 32, pp. 6175-6182, 2015.

[64] J. Lai, W. Niu, R. Luque, and G. Xu, "Solvothermal synthesis of metal nanocrystals and their applications," Nano Today, vol. 10, no. 2, pp. 240-267, 2015.

[65] G. Demazeau, "Solvothermal reactions: an opening-up on the synthesis of novel materials or the development of new processes," High Pressure Research, vol. 27, no. 1, pp. 173-177, 2007.

[66] M. Niederberger and N. Pinna, Metal Oxide Nanoparticles in Organic Solvents: Synthesis, Formation, Assembly and Application, Springer Science \& Business Media, Berlin, Germany, 2009.

[67] B. W. Chieng and Y. Y. Loo, "Synthesis of $\mathrm{ZnO}$ nanoparticles by modified polyol method," Materials Letters, vol. 73, pp. 78-82, 2012.

[68] J. Lian, Y. Liang, F.-L. Kwong, Z. Ding, and D. H. L. Ng, "Template-free solvothermal synthesis of $\mathrm{ZnO}$ nanoparticles with controllable size and their size-dependent optical properties," Materials Letters, vol. 66, no. 1, pp. 318-320, 2012.

[69] H. Wang, C. Xie, and D. Zeng, "Controlled growth of $\mathrm{ZnO}$ by adding $\mathrm{H}_{2} \mathrm{O}$," Journal of Crystal Growth, vol. 277, no. 1-4, pp. 372-377, 2005.

[70] M. Bitenc and Z. Crnjak Orel, "Synthesis and characterization of crystalline hexagonal bipods of zinc oxide," Materials Research Bulletin, vol. 44, no. 2, pp. 381-387, 2009.

[71] S. Li, S. Meierott, and J. M. Köhler, "Effect of water content on growth and optical properties of $\mathrm{ZnO}$ nanoparticles generated in binary solvent mixtures by micro-continuous flow synthesis," Chemical Engineering Journal, vol. 165, no. 3, pp. 958-965, 2010.

[72] J. Wang, C. Loose, J. Baxter et al., "Growth promotion by $\mathrm{H}_{2} \mathrm{O}$ in organic solvent-selective isolation of a target polymorph," Journal of Crystal Growth, vol. 283, no. 3-4, pp. 469-478, 2005. 
[73] E. M. Wong, J. E. Bonevich, and P. C. Searson, "Growth kinetics of nanocrystalline $\mathrm{ZnO}$ particles from colloidal suspensions," The Journal of Physical Chemistry B, vol. 102, no. 40, pp. 77707775, 1998.

[74] E. M. Wong, P. G. Hoertz, C. J. Liang, B.-M. Shi, G. J. Meyer, and P. C. Searson, "Influence of organic capping ligands on the growth kinetics of $\mathrm{ZnO}$ nanoparticles," Langmuir, vol. 17, no. 26, pp. 8362-8367, 2001.

[75] Z. Hu, G. Oskam, and P. C. Searson, "Influence of solvent on the growth of $\mathrm{ZnO}$ nanoparticles," Journal of Colloid and Interface Science, vol. 263, no. 2, pp. 454-460, 2003.

[76] Z. Hu, G. Oskam, R. L. Penn, N. Pesika, and P. C. Searson, "The influence of anion on the coarsening kinetics of $\mathrm{ZnO}$ nanoparticles," Journal of Physical Chemistry B, vol. 107, no. 14, pp. 3124-3130, 2003.

[77] N. S. Pesika, K. J. Stebe, and P. C. Searson, "Relationship between absorbance spectra and particle size distributions for quantumsized nanocrystals," Journal of Physical Chemistry B, vol. 107, no. 38, pp. 10412-10415, 2003.

[78] E. Hosono, S. Fujihara, T. Kimura, and H. Imai, "Growth of layered basic zinc acetate in methanolic solutions and its pyrolytic transformation into porous zinc oxide films," Journal of Colloid and Interface Science, vol. 272, no. 2, pp. 391-398, 2004.

[79] A. Opalinska, C. Leonelli, W. Lojkowski et al., "Effect of pressure on synthesis of Pr-doped zirconia powders produced by microwave-driven hydrothermal reaction," Journal of Nanomaterials, vol. 2006, Article ID 98769, 8 pages, 2006.

[80] http://science24.com/fw145m/.

[81] A. Clearfield, J. Reibenspies, and N. Bhuvanesh, Principles and Applications of Powder Diffraction, Wiley-Blackwell, 2008.

[82] K. Venkateswarlu, D. Sreekanth, M. Sandhyarani, V. Muthupandi, A. C. Bose, and N. Rameshbabu, "X-ray peak profile analysis of nanostructured hydroxyapatite and fluorapatite," International Journal of Bioscience, Biochemistry and Bioinformatics, vol. 2, pp. 389-393, 2012.

[83] R. Pielaszek, " $F W 1 / 5 / 4 / 5 M$ method for determination of the grain size distibution form powder diffraction line profile," Journal of Alloys and Compounds, vol. 382, no. 1-2, pp. 128-132, 2004.

[84] http://science24.com/xrd.

[85] S. Tamari and A. Aguilar-Chávez, "Optimum design of the variable-volume gas pycnometer for determining the volume of solid particles," Measurement Science and Technology, vol. 15, no. 6, pp. 1146-1152, 2004.

[86] K. Heister, "The measurement of the specific surface area of soils by gas and polar liquid adsorption methods-limitations and potentials," Geoderma, vol. 216, pp. 75-87, 2014.

[87] T. Wejrzanowski, R. Pielaszek, A. Opalińska, H. Matysiak, W. Łojkowski, and K. J. Kurzydłowski, "Quantitative methods for nanopowders characterization," Applied Surface Science, vol. 253, no. 1, pp. 204-208, 2006.

[88] W. Pabst and E. Gregorová, Characterization of Particles and Particle Systems, Institute of Chemical Technology in Prague, Prague, Czech Republic, 2007.

[89] S. J. Gregg and K. S. W. Sing, Adsorption, Surface Area and Porosity, Academic Press, London, UK, 2nd edition, 1982.

[90] D. Smoleń, T. Chudoba, S. Gierlotka et al., "Hydroxyapatite nanopowder synthesis with a programmed resorption rate," Journal of Nanomaterials, vol. 2012, Article ID 841971, 9 pages, 2012.
[91] A. Opalinska, I. Malka, W. Dzwolak, T. Chudoba, A. Presz, and W. Lojkowski, "Size-dependent density of zirconia nanoparticles," Beilstein Journal of Nanotechnology, vol. 6, no. 1, pp. 27-35, 2015.

[92] X. Yu and Z. Zhan, "The effects of the size of nanocrystalline materials on their thermodynamic and mechanical properties," Nanoscale Research Letters, vol. 9, no. 1, article 516, pp. 1-6, 2014.

[93] F. Hai-Bo, Z. Xin-Liang, W. Si-Cheng, L. Zhi-Gang, and Y. He$\mathrm{Bao}$, " $\mathrm{Zn} / \mathrm{O}$ ratio and oxygen chemical state of nanocrystalline $\mathrm{ZnO}$ films grown at different temperatures," Chinese Physics $B$, vol. 21, no. 3, Article ID 038101, 5 pages, 2012.

[94] D. Sibera, R. Jędrzejewski, J. Mizeracki, A. Presz, U. Narkiewicz, and W. Łojkowski, "Synthesis and characterization of ZNO doped with $\mathrm{Fe}_{2} \mathrm{O}_{3}$-hydrothermal Synthesis and Calcination Process," Acta Physica Polonica A, vol. 116, pp. S133-S135, 2009.

[95] S. Bhasha, P. Malik, S. Santosh, and J. Purnima, "Synthesis and characterization of nanocrystalline zinc oxide thin films for ethanol vapor sensor," Nanomedicine Nanotechnology Journals, vol. 6, article 306, 2015.

[96] F. Varenne, A. Makky, M. Gaucher-Delmas, F. Violleau, and C. Vauthier, "Multimodal dispersion of nanoparticles: a comprehensive evaluation of size distribution with 9 size measurement methods," Pharmaceutical Research, vol. 33, pp. 1220-1234, 2016.

[97] M. Baghbanzadeh, S. D. Skapin, Z. C. Orel, and C. O. Kappe, "A critical assessment of the specific role of microwave irradiation in the synthesis of $\mathrm{ZnO}$ micro- and nanostructured materials," Chemistry-A European Journal, vol. 18, no. 18, pp. 5724-5731, 2012.

[98] J. S. Schanche, "Microwave synthesis solutions from personal chemistry," Molecular Diversity, vol. 7, no. 2, pp. 291-298, 2003.

[99] J. Wojnarowicz, T. Chudoba, D. Smoleń, W. Łojkowski, A. Majcher, and A. Mazurkiewicz, "Examples of the nanoparticles produced by microwave solvothermal synthesis (MSS) route," Glass and Ceramics, vol. 65, pp. 8-11, 2014.

[100] P. Tonto, O. Mekasuwandumrong, S. Phatanasri, V. Pavarajarn, and P. Praserthdam, "Preparation of $\mathrm{ZnO}$ nanorod by solvothermal reaction of zinc acetate in various alcohols," Ceramics International, vol. 34, no. 1, pp. 57-62, 2008. 

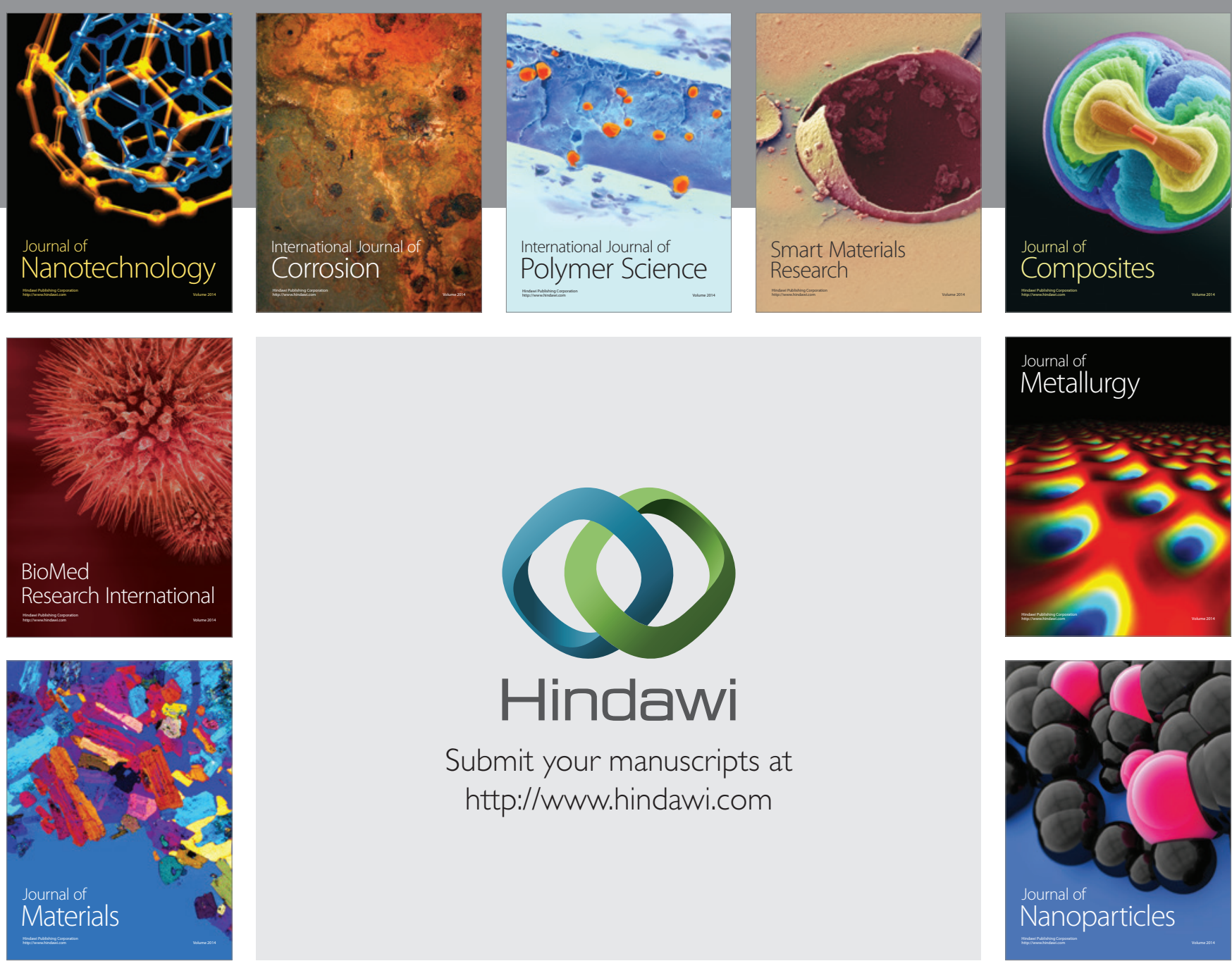

\section{Hindawi}

Submit your manuscripts at

http://www.hindawi.com

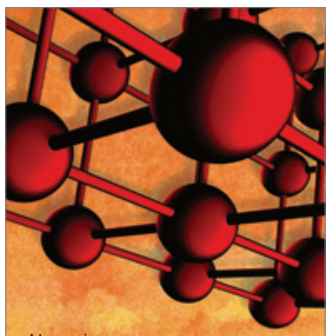

Materials Science and Engineering
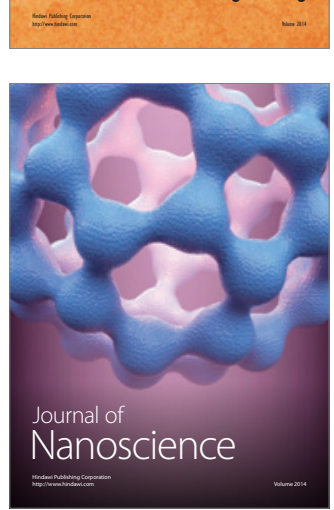
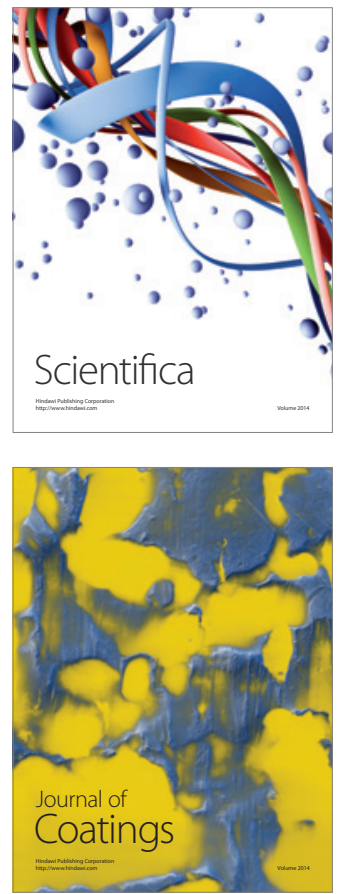
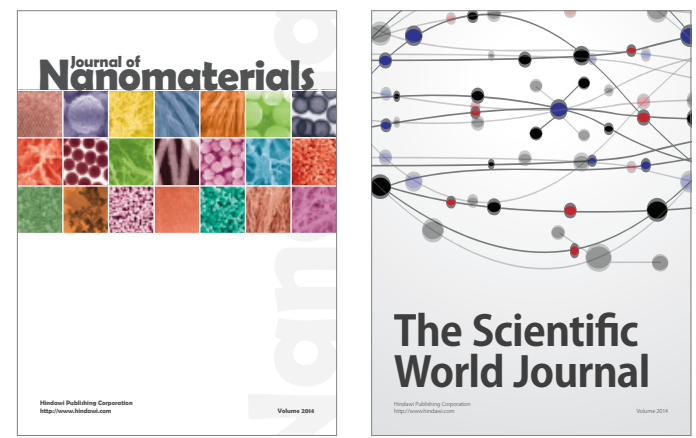

The Scientific World Journal
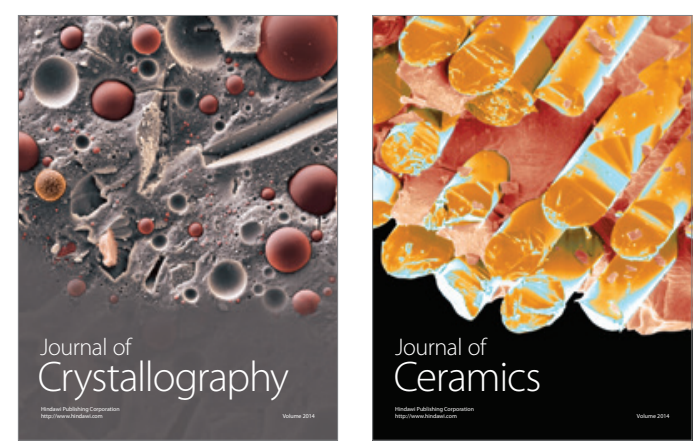
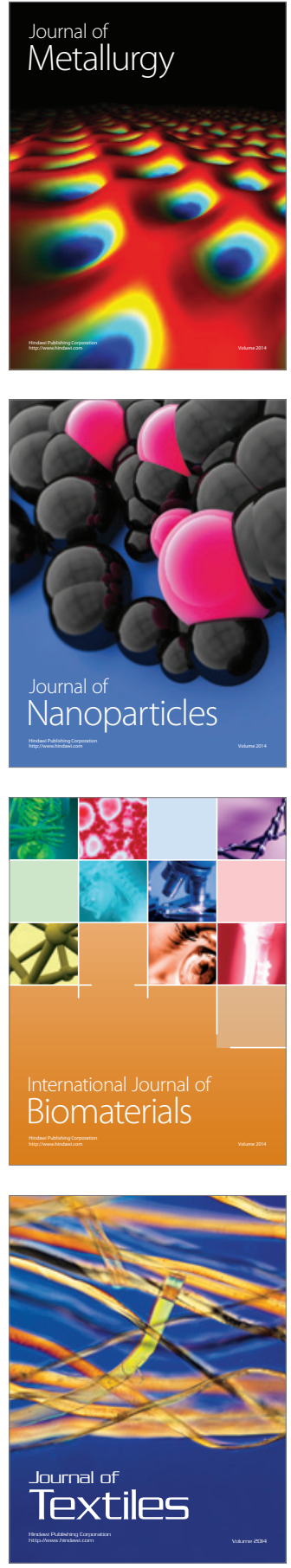